\title{
Effects on the fetus and newborn of maternal analgesia and anesthesia: a review
}

[Les effets de l'analgésie et de l'anesthésie de la mère sur le fatus et le nouveau-né: une revue]

Judith Littleford MD BSc FRCPC

Purpose: To review the effects of maternal anesthesia and analgesia on the fetus and newborn.

Methods: An on-line computerized search of Medline, Embase, and the Cochrane Collaboration via PubMed was conducted. English language articles were selected. The bibliographies of relevant articles and additional material from other published sources were retrieved and reviewed.

Principal findings: No one test clearly separates the effects on the fetus/newborn, if any, of maternally administered medication during labour and delivery, or during surgery for non-obstetric indications. Supposition in this regard is limited in part by methodology previously used to study the transplacental passage of various drugs. This work needs to be repeated using a human model. Routine maternal supplemental oxygen administration is being questioned in light of research showing that free radical generation and oxidative stress are implicated as the underlying mechanisms in several neonatal conditions. Maternal hypotension is associated with neonatal acidemia and base excess correlates with neonatal outcome. Common postpartum analgesics transfer minimally into breast milk. Maternal or fetal surgery conducted during pregnancy necessitates modification of both anesthetic and surgical approaches. The key to resuscitation of the fetus is resuscitation of the mother: intra-uterine maneuvers, including perimortem Cesarean section, aim to reverse treatable causes of fetal asphyxia, restore fetal oxygenation, and correct fetal acidosis.

Conclusions: The well-being of the infant is a major criterion for evaluating the anesthetic management of pregnant women. Many tools exist to assist with this determination for the fetus, whereas few are available to evaluate the newborn.
Objectif : Passer en revue les effets de l'anesthésie et de l'analgésie de la mère sur le fœetus et le nouveau-né.

Méthode : Une recherche informatisée en ligne des bases Medline et Embase et du Centre de collaboration Cochrane via PubMed a été réalisée. Des articles de langue anglaise ont été sélectionnés. Les bibliographies d'articles pertinents et du matériel additionnel d'autres publications ont été retenus et passés en revue.

Constatations principales: Aucun test ne sépare clairement les effets sur le fœetus/nouveau-né, si effet il y a, des médicaments administrés à la mère pendant le travail et l'accouchement ou pendant une intervention chirurgicale non obstétricale. Les hypothèses possibles dans ce contexte sont limitées en partie par la méthodologie antérieurement utilisée pour étudier le passage transplacentaire de différents médicaments. On doit répéter ces essais sur un modèle humain. L'administration courante d'un supplément d'oxygène à la mère est remise en question par la recherche qui montre que la génération de radicaux libres et le stress oxydatif font partie des mécanismes sous-jacents de certaines pathologies du nouveau-né. L'hypotension maternelle est associée à l'acidémie néonatale et l'excès basique est en corrélation avec l'évolution néonatale. Les analgésiques utilisés habituellement en postpartum passent très peu dans le lait maternel. Une intervention chirurgicale maternelle ou fotale pendant la grossesse nécessite une modification des approches anesthésique et chirurgicale. La clé de la réanimation du foetus est la réanimation de la mère : les manœuvres intra-utérines, y compris la césarienne périmortem, ont pour but de renverser les causes de l'asphyxie fotale, de restaurer l'oxygénation foetale et de corriger l'acidose fœtale.

Conclusion : Le bien-être de l'enfant est un critère majeur de l'évaluation de la démarche anesthésique chez la femme enceinte. Dans ce but, de nombreux outils existent pour le fœetus, mais peu pour évaluer le nouveau-né.

From the Department of Anesthesia, University of Manitoba, Winnipeg, Manitoba, Canada. Address correspondence to: Dr. Judith Littleford, GH 611- Department of Anesthesia, Health Sciences Centre, 820 Sherbrook Street, Winnipeg, Manitoba R3A 1R9, Canada. Phone: 204-787-3796; Fax: 204-787-3656; E-mail: heyjude@mts.net Accepted for publication December 9, 2003. Revision accepted March 24, 2004. 
B ETWEEN the mid 1800's and the 1950's, descriptive reports of the presumed effect of maternally administered medication on the fetus and newborn appeared sporadically in the literature. Two developments eventually encouraged physicians to acknowledge the potential problems associated with placental transmission of anesthetic drugs: ${ }^{1}$

1. Recognition that morphine, a popular ingredient of patent medicines, was addictive, and that signs of withdrawal could be identified in the fetus (violent fetal movements and/or sudden fetal death), when the mother's heavy opioid use was decreased.

2. Confirmation of the structure and dynamic function of the placenta and, demonstration of the presence of chloroform in the umbilical blood of neonates.

\section{TABLE OF CONTENTS}

PART I: ANALGESIA FOR LABOUR

Evaluation of fetal and neonatal well-being

- The Apgar score

- Umbilical cord blood gas analysis

- Evaluation of newborn neurobehaviour

- Electronic fetal monitoring

- Biophysical profile score

- Fetal pulse oximetry

- Fetal Doppler

Labour pain

- Static charge-sensitive bed

- Implications for the fetus

Analgesic techniques for labour: effects on the fetus and newborn

- Nonpharmacologic methods

- Systemic opioids

- Agonist-antagonist opioids

- Nitrous oxide

- Paracervical block

- Neuraxial analgesia

OPIOIDS

LOCAL ANESTHETICS

COMBINING OPIOIDS, LOCAL ANESTHETICS AND

PAIN-RELIEVING ADJUVANTS

\section{Labour epidurals and outcome}

- Instrumental delivery

- Delayed pushing

- Maternal fever

- Breastfeeding
In 1952, the pioneering work of anesthesiologist Virginia Apgar converted an intangible phenomenon, the clinical condition of a newly born baby, into a formally defined measurement. ${ }^{2}$ Thereafter, the wellbeing of the infant became a major criterion for evaluation of the obstetric and anesthetic management of pregnant women.

The purpose of this article is to review the effects of maternal anesthesia and analgesia on the fetus and newborn and convey this information according to the outline presented in the following Table of Contents.

\section{PART II: ANESTHESIA FOR SURGERY}

Anesthetic techniques for Cesarean section: effects on the fetus and newborn

- General anesthesia

- Regional anesthesia

- Fetal effects of maternal oxygen administration

Postpartum pain management

Surgery during pregnancy

Fetal surgery

Resuscitation during pregnancy

- Intra-uterine resuscitation of the compromised fetus

- Maternal cardiac arrest

- Perimortem Cesarean section

\section{Conclusion}




\section{PART I: ANALGESIA FOR LABOUR}

\section{Evaluation of fetal and neonatal well-being}

Several methods of evaluation have been used by anesthesiologists in an attempt to separate out the fetal/neonatal effects of their interventions from concomitant medical and nursing management, and from the influence of pre-existing maternal conditions.

\section{The Apgar score}

The Apgar score rates each of five physical signs traditionally used by anesthesiologists to monitor a patient's condition: heart rate, respiratory effort, muscle tone, reflex irritability, and colour, at one, five, and ten minutes after birth. The results depict the status of the newborn and, when scores are compared, the effectiveness of resuscitation. The numerical composite is partly dependent on the physiologic maturity of the infant. Likewise, neonatal conditions such as bradyarrhythmias affect heart rate, while infection, neuromuscular conditions, and certain medications affect respiratory effort and tone.

Apgar demonstrated that her score was sufficiently sensitive to detect differences among newborns whose mothers had received spinal $v s$ general anesthesia for Cesarean section. ${ }^{2}$ It is used to assess the condition of the infant at birth, ${ }^{3}$ it is not specific for the effects of anesthesia on the newborn.

\section{Umbilical cord blood gas analysis}

Cord blood gas analysis is the gold standard for assessing fetal acid-base status and uteroplacental function at birth. Umbilical artery $\mathrm{pH}$, base excess, and $\mathrm{pCO}_{2}$ reflect fetal and immediate neonatal condition whereas umbilical vein values reflect maternal acid-base status and placental function.

"Normal" values vary depending on the definition of normality and the influence of factors (for example, altitude, parity, breech vaginal delivery, and duration of labour) on the population studied. ${ }^{4}$ Helwig et al. ${ }^{5}$ retrospectively examined the records of 15,000 vigorous newborns with a five-minute Apgar score of $>7$. Median umbilical artery values, with the 2.5 th percentile value in parentheses, were $\mathrm{pH} 7.26$ (7.10) and base excess $-4 \mathrm{mmol} \cdot \mathrm{L}^{-1}\left(-11 \mathrm{mmol} \cdot \mathrm{L}^{-1}\right)$. The means \pm 2 standard deviations were similar. The generally accepted lower limit of normal umbilical artery $\mathrm{pH}$ extends to 7.10 and base excess to $-12 \mathrm{mmol} \cdot \mathrm{L}^{-1}$. 4,6

Values for $\mathrm{pH}, \mathrm{pCO}_{2}$, and base excess also vary with differences in sampling technique. Pre-analytical error can be introduced if the cord is not clamped immediately, there is an excess quantity of heparin in relation to the amount of blood collected, air is present in the syringe, or the sample is kept at room temperature for longer than 15 min. $^{7}$

The supply of oxygen and the removal of volatile $\left(\mathrm{CO}_{2}\right)$ and fixed (for example, lactate) acids by the placenta for excretion by the maternal lungs and kidneys, respectively, allow the fetus to maintain acid-base balance within a narrow range. Interruption of these processes can lead to acidemia in the fetus. In general, respiratory acidosis alone is not associated with newborn complications; rather, it reflects a sudden decrease in uteroplacental or umbilical perfusion such as placental abruption or cord prolapse immediately preceding delivery. Base excess values have greater usefulness than $\mathrm{pH}$ values because base excess does not change significantly with respiratory acidosis and demonstrates linear, rather than logarithmic, correlation to the degree of metabolic acidosis. Umbilical artery base excess is the most direct measure of fetal metabolic acidosis. Human and animal studies have confirmed normal values before and during labour and rates of base excess change in relation to events causing fetal hypoxemia (maternal hypoxemia, umbilical cord occlusion, and reduced uterine blood flow). ${ }^{6}$

The process of normal labour and delivery without anesthetic intervention stresses the fetus such that mild acidosis develops in almost all labours. ${ }^{8}$ Reynolds et al. recently completed a meta-analysis comparing epidural with systemic opioid analgesia to determine the effect of these anesthetic interventions on acidbase status at birth. ${ }^{9}$ They concluded that epidural analgesia was associated with an improvement in base excess, suggesting that placental exchange is well preserved in association with this technique.

While umbilical artery $\mathrm{pH}$, base excess, and $\mathrm{pCO}_{2}$ are considered sensitive and objective indicators of fetal hypoxia during labour, the results represent a "snapshot" of fetal status and depict the mixed effluent of all fetal tissues. Cord gases do not distinguish between primary fetal pathologic conditions, fetal effects of maternal conditions (for example, acid-base disorders), or the influence of inadequate placental blood flow. They also do not indicate in which direction the condition of the fetus is moving, or at what rate, nor do they reflect events that occurred remote from delivery.

\section{Evaluation of newborn neurobehaviour}

Brazelton, Scanlon, and Amiel-Tison assessed the effect of anesthetic medications on the neurobehaviour of term, healthy newborns. ${ }^{10-12}$ Their belief was that central nervous system depression from drugs administered to the mother during labour and delivery could be distinguished from effects associated with 


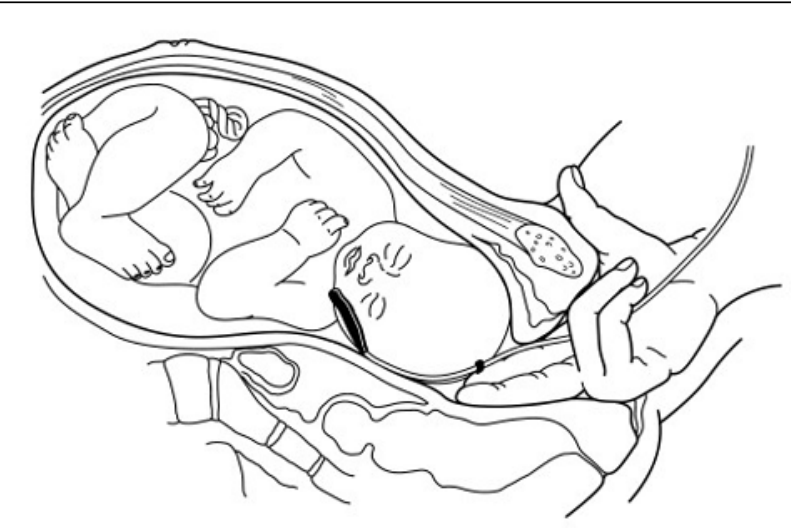

FIGURE 1 OxiFirst ${ }^{\mathrm{TM}}$ Fetal Pulse Oximetry. Reprinted with permission from TycoHealthcare. Copyright 2000 Mallinckrodt, Inc. All rights reserved.

perinatal asphyxia and trauma at birth. Several review articles have described these tests in detail and compared the Brazelton Neonatal Behavioral Assessment Scale (NBAS) $)^{10}$ and Early Neonatal Neurobehavioral Scale $(\mathrm{ENNS})^{11}$ to the Neurologic and Adaptive Capacity Score (NACS). ${ }^{12}$

Researchers in obstetric anesthesia have tended to favour the NACS. A systematic review of the literature regarding use of the NACS in obstetric anesthesia research concluded that reliability and validity evaluations of the tool were lacking and it was unclear whether the NACS could detect the existence of subtle neurobehavioural effects. ${ }^{13}$ Subsequently, it has been determined that the NACS has poor reliability when used to detect the effects of intrapartum drugs and other interventions on the neonate. ${ }^{14}$

\section{Electronic fetal monitoring}

Electronic fetal monitoring, one technique in the overall strategy of intrapartum fetal surveillance, ${ }^{15,16}$ aims to improve outcomes by identifying fetuses with hypoxic acidemia at a point when the process is still completely reversible by intra-uterine resuscitation or expedited delivery. The fetal heart rate (FHR), including variability, accelerations, and decelerations, if any occur, is recorded electronically on a paper trace. Baseline FHR normally ranges between 110 to 160 beats. $\mathrm{min}^{-1}$. A reactive (normal or reassuring) cardiotocogram (CTG) is defined by the presence of accelerations. Reduced variability and the presence of decelerations are abnormal findings.

A systematic review of studies comparing the efficacy and safety of routine continuous electronic fetal monitoring $v s$ intermittent auscultation of the FHR reveals the former to be associated with a significantly higher rate of Cesarean and operative vaginal delivery. ${ }^{17}$ In the antecedent Cochrane review of this same topic, the incidence of general anesthesia to facilitate obstetric intervention was also increased. This aspect of management was not examined in the current review.

Difficulty in the visual interpretation of CTG patterns during labour can result in unnecessary operative intervention, while some significant changes go unrecognized. Computerized CTG systems, which do not rely on observer reading of the FHR tracing, are more accurate and reliable. Evaluation of the FHR pattern is given on-line continuously and warnings are displayed if there is signal loss, reduction in fetal movements, or an abnormally flat or decelerative trace. ${ }^{18}$ Retrospective analysis of several thousand records enabled investigators to conclude that the most reliable single parameter of fetal condition was variability (short- and long-term). Absence of accelerations, presence of decelerations, decrease in the number of movements, and changes in baseline FHR all occurred occasionally in normal fetuses. ${ }^{19}$

Recently, automatic ST segment and T wave analysis of the fetal electrocardiogram (ECG; recorded continuously from a fetal scalp electrode) has been combined with conventional CTG. Elevation or depression of the ST segment occurs when the fetus is exposed to a hypoxic stress. When CTG is accompanied by computerized analysis of the ST segment, the number of operative deliveries for the indication of "fetal distress" can be reduced without jeopardizing fetal outcome and, cases of significant fetal hypoxia necessitating obstetric intervention are more readily identified. ${ }^{19,20}$

Anesthesiologists have used continuous fetal CTG recordings to evaluate the effect of maternal analgesia on FHR and variability. Solt et al. demonstrated that intrapartum $i v$ administration of meperidine (pethidine) $50 \mathrm{mg}$ and promethazine $25 \mathrm{mg}$ resulted in decreased variability and fewer accelerations on computerized CTG for the duration of their $40 \mathrm{~min}$ recording. ${ }^{21}$ It is unclear whether the effect can be attributed to one of the two drugs or the combination, although this is a typical fetal response to systemic maternal opioid administration.

A randomized study was conducted to examine the effect of continuous epidural anesthesia with or without narcotic on intrapartum FHR characteristics as measured by computer analysis. The narcotic epidural consisted of an initial bolus of 10 to $12 \mathrm{~mL} 0.125 \%$ bupivacaine with $50 \mu \mathrm{g}$ fentanyl, followed by continuous bupivacaine $0.125 \%$ with fentanyl $1.7 \mu \mathrm{g} \cdot \mathrm{mL}^{-1}$ infu- 
sion. The non-narcotic epidural was initiated with a bolus of 10 to $12 \mathrm{~mL}$ bupivacaine $0.25 \%$ and followed by a bupivacaine $0.125 \%$ infusion. Investigators found no difference in pre- and post-epidural baseline FHR, accelerations, or variability between the groups. ${ }^{22}$

In a double-blind randomized study of bolus epidural opioid effect on FHR variability, butorphanol $2 \mathrm{mg}$, fentanyl $50 \mu \mathrm{g}$, sufentanil $15 \mu \mathrm{g}$, or saline in combination with bupivacaine $0.25 \%$ did not change FHR short- or long-term variability. ${ }^{23}$

FHR decreases in response to compression of the fetal head during passage through the birth canal, and in response to umbilical cord compression or reduced uterine blood flow secondary to maternal hypotension or prolonged uterine contraction. This bradycardia is vagally mediated.

\section{Biophysical profile score}

This ultrasound-based method combines measures of acute biophysical variables, fetal breathing, heart rate accelerations, gross body movements, and fetal tone with amniotic fluid volume. ${ }^{24}$ The first four variables reflect acute fetal condition, whereas the last variable reflects chronic fetal condition. The observation period lasts $30 \mathrm{~min}$ because fetuses are known to sleep for intervals lasting $\sim 30 \mathrm{~min}$. When normal ( $\geq 8$ out of a possible10), the biophysical profile score (BPS) is a direct, reliable, and accurate measure of normal tissue oxygenation. A normal score is never associated with an abnormal fetal $\mathrm{pH}$. Scores $\leq 6 / 10$ during routine antepartum evaluation indicate the amount of oxygen delivered to target organs is insufficient to maintain function. The lower the score, the greater the likelihood that central acidemia is present. ${ }^{25}$

Placental transfer to the fetus of maternally administered im narcotic medication (diamorphine $10 \mathrm{mg}$ or, morphine 10 or $15 \mathrm{mg}$ administered with dimenhydrinate) resulted in transiently reduced fetal activity and, consequently, a lower BPS for the duration of the drug effect. ${ }^{26,27} \mathrm{~A}$ small dose of $i v$ fentanyl $(50 \mu \mathrm{g})$ given in early labour was associated with abolishment of fetal breathing at ten minutes post dosing, fewer body movements, and reduced variability. ${ }^{28}$ The effect lasted $\sim 30 \mathrm{~min}$, in keeping with the pharmacodynamic profile of fentanyl. This should be taken into account when fentanyl is administered close to the time of delivery. In this study, none of the neonates required resuscitation, and all had umbilical artery $\mathrm{pH}$ values $>7.2$.

\section{Fetal pulse oximetry}

Fetal oxygen saturation monitoring by pulse oximetry $\left(\mathrm{SpO}_{2}\right)$ relies on established, non-invasive technology, and is based on the following assumptions: fetal well- being is dependent on perfusion of vital organs with oxygenated blood, $\mathrm{SpO}_{2}$ correlates with saturation as measured by blood gas analysis, and a critical threshold for $\mathrm{SpO}_{2}$ exists, above which the fetus will be non-acidemic and below which, acid-base decompensation may occur. ${ }^{29}$

Based on animal and human data, fetal $\mathrm{SpO}_{2}$ values $\geq 30 \%$ can be considered reassuring, whereas $\mathrm{SpO}_{2}$ values $<30 \%$ may be associated with acidosis. Low $\mathrm{SpO}_{2}$ values warrant further assessment if they persist for periods of more than two minutes and, necessitate intervention (intra-uterine resuscitation or expedited delivery) if they persist for more than ten minutes. ${ }^{20,30}$ The predictive value of intrapartum fetal pulse oximetry compares favourably with fetal scalp blood analysis. $^{31}$ The former has the advantage of being a continuous monitoring technique.

The United States Food and Drug Administration approved the Nellcor N-400/FS14 fetal pulse oximeter for clinical use in 2000 as an adjunct to electronic fetal monitoring in the presence of a nonreassuring tracing. At present, this technology is limited to singleton, term fetuses in the vertex position.

Results of studies designed to investigate the effects on fetal oxygen saturation of administering epidurals to healthy parturients are beginning to appear in the literature. Neither an initial epidural bolus of $15 \mathrm{~mL}$ ropivacaine $0.1 \%$ with sufentanil $10 \mu \mathrm{g}$ or intermittent repeat plain ropivacaine boluses affected $\mathrm{SpO}_{2}$ in healthy fetuses. ${ }^{32}$ In a study designed to account for the possible influence of maternal position, diastolic blood pressure, and pre-existing FHR pattern, $\mathrm{SpO}_{2}$ values were not affected by boluses of dilute epidural infusion solutions, but did decrease with bolus administration of more concentrated local anesthetics (LA) at epidural insertion or top-up..$^{33}$ Other than to comment on the variety of combinations and strengths of analgesic agents, details of the epidural solutions were not contained in the report. Further clinical trials are needed to assess and characterize the effect of all types of anesthetic intervention on fetal pulse oximetry during normal and abnormal labour, in addition to various maternal conditions associated with fetal compromise (for example, pregnancy-induced hypertension).

\section{Fetal Doppler}

Flow velocity waveforms from maternal vessels (uterine arteries), placental circulation (umbilical arteries), and fetal systemic vessels (for example, middle cerebral artery), collectively known as Doppler evaluation, provide prognostic and diagnostic detail about placentation and fetal adaptation. ${ }^{34}$

Regulation of the circulation is a complex fetal behaviour, influenced by gestational age and the 
maternal environment. Under normal circumstances, the reduction in sympathetic tone created by epidural analgesia does not affect Doppler flow characteristics of either the uterine or umbilical artery vessels because the spiral arterioles are maximally dilated and the fetoplacental circulation is stable and tolerant of environmental changes. However, epidural analgesia has been shown to improve uteroplacental perfusion and effectively reduce maternal blood pressure in labouring patients with pregnancy-induced hypertension. ${ }^{35}$

\section{Static charge-sensitive bed (SCSB)}

A method for long-term monitoring of respiration, heart rate, cardiac function, and body movements in newborn infants was presented in 1984 and possible clinical applications were discussed. ${ }^{36}$ The technology has been used to evaluate neonatal sleep states following unmedicated vaginal delivery or elective Cesarean delivery under spinal anesthesia ${ }^{37}$ and, in combination with pulse oximetry and ECG recording, to examine the influence on the newborn baby of maternal fentanyl analgesia in labour. ${ }^{38}$

In the first study, mode of delivery did not affect sleep state distribution during the first day of life. ${ }^{37}$ Vaginally born neonates had fewer body movements and more episodes of $\mathrm{SpO}_{2}<95 \%$ in the first $24 \mathrm{hr}$ after birth. This result surprised the investigators, since babies born by Cesarean section are known to develop respiratory problems more often than infants who are delivered vaginally. In the second study, fentanyl ( $50 \mu \mathrm{g} i v$ bolus every five minutes until pain relief, then fentanyl patient-controlled analgesia) was compared with paracervical block $(10 \mathrm{~mL}$ $0.25 \%$ bupivacaine) in a prospective, randomized fashion. The trial was interrupted after enrollment of the 12th healthy, term newborn because there was a significant decrease in $\mathrm{SpO}_{2}$ to $59 \%$ in one of the babies. Interestingly, the $\mathrm{SpO}_{2}$ improved with naloxone administration even though later analysis showed the concentration of fentanyl in the umbilical vein to be below the detection limit of the assay. Intrapartum electronic fetal monitoring did not reveal any difference in variability or heart rate between groups. As well, Apgar scores and analyses of umbilical artery $\mathrm{pH}$ were similar. The $\mathrm{SpO}_{2}$ values were lower, and the percentage of minimum $\mathrm{SpO}_{2}$ values between 81 and $90 \%$ were more prevalent, in the fentanyl group. The SCSB method proved sensitive enough to detect lower heart rates and less quiet sleep in the fentanyl group, suggesting a salutary effect of the opioid on delivery stress. ${ }^{38}$

\section{Summary}

The nature of the association of anesthetic medications and interventions is complex and can be con- founded by a myriad of factors. As yet, there is no one test that clearly separates effects on the fetus/newborn, if any, of maternally administered medication during labour and delivery, although newer technologies show some promise.

\section{Labour pain}

Labour pain evokes a generalized neuroendocrine stress response that has widespread physiological effects on the parturient and fetus. ${ }^{39}$ The neuroendocrine model, presented in Figure 2, examines the potential detrimental consequences of untreated pain. The sequelae of hyperventilation, secretion of stressrelated hormones, and increased oxygen consumption can be prevented, obtunded, or abolished by central neuraxial blockade (epidural or spinal anesthesia).

Research in humans supports elements of this model, ${ }^{40}$ but studies are not necessarily designed to consider the effects of simultaneously occurring care practices on these same physiologic responses. "This critique is needed because it is somewhat counterintuitive that the procreative physiologic process of labour and birth would by nature have detrimental effects on a healthy mother and fetus". ${ }^{41}$ An example of a concurrent care practice is the administration of isotonic "sport drinks" vs water only during labour. ${ }^{42}$ Sports drinks were shown to prevent the development of maternal ketosis without increasing gastric volume, although there was no difference between the groups in neonatal outcome.

To view labour pain only as a neuroendocrine, sensory experience is limiting and undermines the complexity of this phenomenon. ${ }^{41}$ Pain is just one component of the totality of the labour and birth experience. Assisting women to cope with the affective or distress components of labour and birth in a supportive environment has been shown to reduce the need for pain-relieving drugs, decrease the incidence of operative delivery, result in higher Apgar scores, and improve breastfeeding success. ${ }^{43,44}$

\section{Implications for the fetus}

Neural pathways and neurochemical systems involved in pain perception are functional from mid-gestation, and are well developed by the third trimester. ${ }^{45,46}$ Gitau $e t a l$. conducted a parallel study of the fetal and maternal hormonal response to fetal blood transfusion. They confirmed that the fetus mounts a hypothalamic-pituitary-adrenal response to transfusion via the intrahepatic vein, which involves piercing the fetal trunk, but not to transfusion in the umbilical vein at the placental cord insertion, which has no sensory innervation. ${ }^{47}$ The rise in fetal cortisol and endorphin 


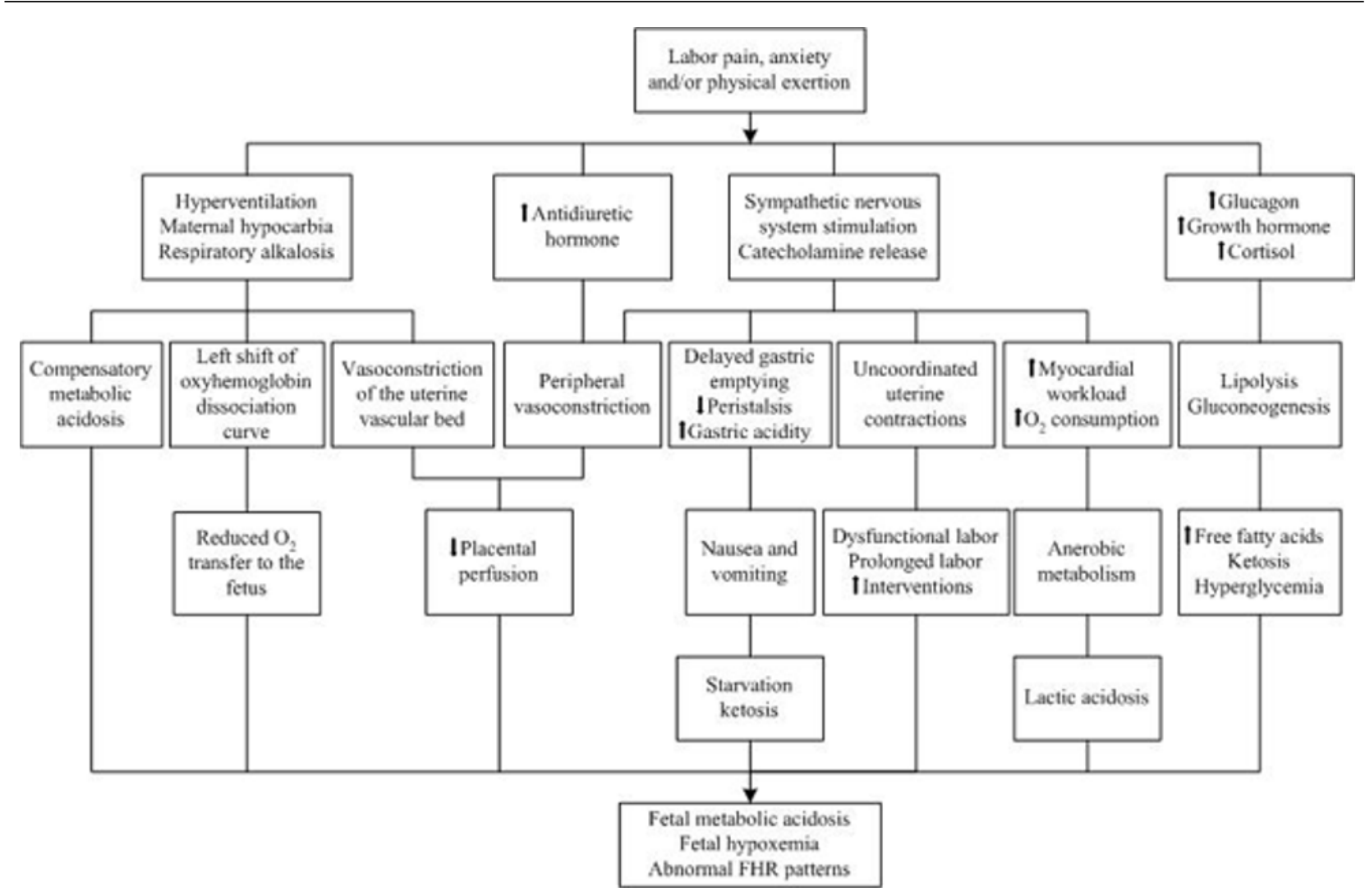

FIGURE 2 Potential adverse effects of untreated maternal pain on the fetus (adapted and modified from: Brownridge P, Cohen SE, Ward $M E$. Neural blockade for obstetrics and gynecologic surgery. In: Cousins MJ, Bridenbaugh PO (Eds). Neural Blockade in Clinical Anesthesia and Management of Pain, 3rd ed. Philadelphia: Lippincott, Williams \& Wilkins; 1998: 557-604).

occurred independently of the maternal reaction. Pretreatment of the fetus with fentanyl for this same procedure attenuated the rise in $B$-endorphin. ${ }^{48}$

Hormonal stress responses do not provide a direct index of pain. While it is true that a rise in cortisol and endorphin is seen as a consequence of painful stimuli in children, other non-painful situations (for example, exercise) are also associated with an increase in the levels of these hormones. Nonetheless, the editorial review of Fisk's fentanyl pretreatment study suggests that fetal analgesia should be given during invasive in utero procedures. ${ }^{49}$

At present, there is no literature on fetal "pain" during labour or delivery.

\section{Analgesic techniques for labour: effects on the fetus and newborn Nonpharmacologic methods}

In a systematic review of comfort measures, Simkin and O'Hara commented on five methods scientifically evaluated for their effectiveness in reducing indicators of labour pain..$^{50}$ Continuous labour support was associated with a decrease in duration of labour, requests for analgesia, rates of instrumental and Cesarean deliveries, and occurrence of lower Apgar scores. The use of baths offered temporary pain relief and was considered safe provided water temperatures were maintained at or below maternal body temperature and that immersion duration was controlled. Perinatal morbidity and mortality did not increase, even if membranes were ruptured. The authors concluded that there had been insufficient study to provide clear conclusions regarding touch/massage, although emo- 


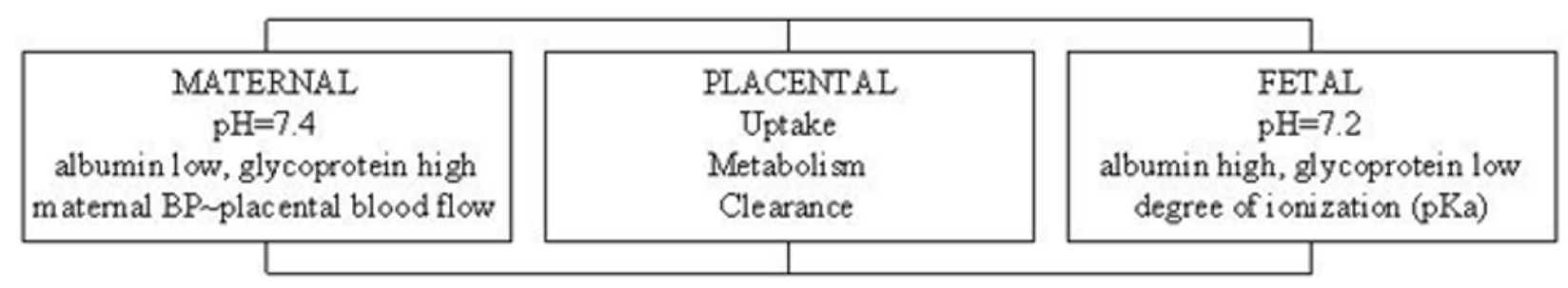

FIGURE 3 Factors influencing fetal drug levels with patient controlled anagesia narcotic administration

Fetal $\mathrm{pH}$ is lower than maternal pH; consequently, the fraction of opioid (and other basic drugs) existing in the ionized state is higher in the fetus than in the mother. Ionization results in drug trapping. The degree of ionization depends on the drug's pKa; the effect is greater for meperidine $(\mathrm{pKa} \sim 8.5)$ than morphine ( $\mathrm{pKa} \sim 8.0$ ), and more significant when the fetus is acidotic, a simplistic, albeit true, application of opioid pharmacokinetics, a complex, difficult to predict, and incompletely evaluated topic.

tional and physical relief was demonstrated with this intervention. Intradermal water blocks were effective in reducing severe back pain, and one randomized study reported a decrease in Cesarean deliveries. Lastly, maternal movement and positioning was reported to impact on pain relief in labour and on several variables related to fetal and neonatal well-being. ${ }^{51}$

\section{Systemic opioids}

From the maternal perspective, efficacy and incidence of side effects with systemic opioid analgesia is largely dose- rather than drug-dependent. There is little evidence to suggest one agent is intrinsically superior. Most often, the choice is based on institutional tradition or personal preference.

Opioids may affect the fetus directly, as a result of placental transfer, and/or indirectly, for example, by altering maternal minute ventilation or uterine tone. As a group, these low molecular weight drugs are lipid-soluble weak bases that readily cross the placenta. ${ }^{52}$ This implies that maternal to fetal concentration gradients are important; only free, not protein bound, drug is available for transfer. The amount of "free" drug delivered to the placenta depends on placental blood flow and the degree of maternal protein binding. The amount of drug available to the fetus depends on the degree of placental uptake, metabolism and clearance. ${ }^{53}$ In single-dose drug studies, key factors influencing umbilical vein/maternal drug ratio are lipid solubility and transit time through the placental bed. In multi-drug dosing (for example, patient controlled narcotic analgesia delivery systems [PCA]), key factors influencing fetal drug levels are the degree of ionization and the degree of fetal protein binding (Figure 3).
All opioids have the potential to decrease baseline FHR and reduce variability, making interpretation of fetal CTG recordings potentially problematic. It has been documented from observational studies that parenteral narcotics can be associated with neonatal respiratory depression, decreased neonatal alertness, inhibition of sucking, and a delay in effective feeding. When evidence related to the use of parenteral opioids for labour pain relief was subject to a systematic review, ${ }^{54}$ it was noted that none of the studies was sufficiently powered to address the primary outcome measure of neonatal resuscitation, a measure of safety. Intramuscular opioid was compared to placebo, different $i m$ opioid, same $i m$ opioid but different dose, and same opioid given intravenously. Intravenous opioid was compared to different $i v$ opioid and same $i v$ opioid but different modes of administration. There was insufficient pooled information to draw conclusions regarding any of the secondary outcome measures, including fetal distress, administration of naloxone, Apgar score $<7$ at five minutes, neonatal mortality, admission to a special care setting, feeding problems, and problems with mother-baby interaction.

Meperidine is the most commonly used opioid for labour analgesia worldwide. It has been shown that, as the time increases from administration of single-dose, im meperidine $1.5 \mathrm{mg} \cdot \mathrm{kg}^{-1}$ during labour to delivery of the baby, so too does the level of meperidine in the fetus. ${ }^{55}$ Maximum fetal concentrations reach a plateau between one to five hours after dosing; therefore, babies born within one to five hours after meperidine is given to the mother have the greatest risk of narcotic-induced depression. In contrast to single-dose studies, multiple doses of meperidine administered over many hours lead to accumulation of its metabo- 
lite, normeperidine, in the mother and fetus. ${ }^{56}$ Halflives of 17 to $25 \mathrm{hr}$ for this metabolite are common in the mother, whereas the half-life exceeds $60 \mathrm{hr}$ in the fetus/newborn. Normeperidine is associated with respiratory depression that is not reversible by naloxone, and seizures.

Fentanyl offers prompt analgesia coupled with a short duration of action and no active metabolites. Both maternal and fetal drug levels decline in a parallel fashion following a single dose of the drug. ${ }^{57}$ In the first report of its administration to labouring patients, fentanyl $(50-100 \mu \mathrm{g} i \mathrm{v}$ every hour) was compared with meperidine $(25-50 \mathrm{mg}$ iv q $2-3 \mathrm{hr}) .{ }^{58}$ More mothers were nauseated and sedated and more babies required naloxone in the meperidine group.

Sufentanil is the most lipid soluble (octanol:water partition coefficient 1778) of the commonly used opioids. ${ }^{52}$ This feature should enhance placental transfer after a single dose, but transfer is impeded by the extent of maternal plasma protein binding $\left(\alpha_{1}\right.$-acid glycoprotein) and uptake by the placenta. Sufentanil concentration in the fetus rises slowly, reaching a plateau between 45 and 80 min post-administration. ${ }^{59}$ It is a useful maternal analgesic for pain relief during second stage, when fetal delivery is imminent ( $<45 \mathrm{~min})$.

Remifentanil has the most rapid onset of peak effect, shortest context-sensitive half time, and greatest clearance of the commonly used opioids. ${ }^{52}$ Its concentration decreases by $50 \%$ within three to five minutes of stopping drug administration, regardless of the duration of the infusion. ${ }^{52}$ The drug rapidly crosses the placenta and is quickly metabolized by fetal esterases. ${ }^{60}$ Reduced FHR variability has been observed. ${ }^{61}$ Newborns exposed to remifentanil in utero up until the time of delivery have been vigorous. There have been no reports of lower Apgar scores, unacceptable umbilical cord gas analyses, or respiratory depression necessitating naloxone use. ${ }^{60,62,63}$

Naloxone is used to reverse respiratory depression in narcotic-exposed newborns. It is contraindicated for infants of narcotic-dependent mothers, as administration may precipitate acute withdrawal and seizures. Naloxone has never been shown to reduce the need for assisted mechanical ventilation or reduce admission rates to special care nurseries. ${ }^{64}$ No studies have evaluated the effect of naloxone on time to spontaneous effective respiration or long-term outcome.

\section{Agonist-antagonist opioids}

Nalbuphine is commonly used as a systemic analgesic during labour. Reports of severe perinatal cardiovascular and respiratory depression prompted Nicolle et $a l .{ }^{65}$ to carry out a study designed to delineate placen- tal transfer and disposition of nalbuphine in the neonate. The estimated half-life was $4.1 \mathrm{hr}$ ( $v$ s $0.9 \mathrm{hr}$ in infants and two hours in adults). Given that the liver extensively metabolizes nalbuphine, the authors speculated that the slower neonatal plasma disappearance rate compared to the infant or adult could be due in part to immature hepatic function or bypass of the liver via the ductus venosus. All 28 babies had fiveminute Apgar scores of 10. Fifty-four percent of the FHR tracings showed reduced variability lasting 10 to 35 min after maternal injection.

One potential use for this class of drugs is in the treatment of opiate-dependent pregnant women. Babies born to mothers on a buprenorphine maintenance program showed little or no clinically measurable neonatal abstinence syndrome in contrast to findings with methadone, morphine, or heroin maintenance programs. ${ }^{66}$

\section{Nitrous oxide $\left(\mathrm{N}_{2} \mathrm{O}\right)$}

$\mathrm{N}_{2} \mathrm{O}$ readily crosses the placenta. The maternal-fetal concentration ratio reaches 0.8 within 15 min of continuous inhalation. It has no effect on uterine contractions or FHR. It is not metabolized, and is eliminated quickly and entirely by the lungs with the onset of respiration at birth. This is true whether the mother inhales $\mathrm{N}_{2} \mathrm{O}$ for five minutes or five hours. $\mathrm{N}_{2} \mathrm{O}$ does not affect Apgar scores or sucking behaviour. ${ }^{67}$ Inhalation analgesia with $\mathrm{N}_{2} \mathrm{O}$ during labour and delivery, as the primary analgesia method, as a coanalgesic, or as a temporizing measure pending other forms of pain relief is less common in the United States than in other developed countries.

\section{Paracervical block}

This peripheral block provides a therapeutic alternative for first stage labour pain when central neuraxial blockade is contraindicated or unavailable. The technique involves transvaginal injection of LA on either side of the cervix in order to interrupt pain transmission at the level of the uterine and cervical plexuses (located at the base of the broad ligament). Paracervical block (PCB) is relatively easy to perform and, when effective, it provides good to excellent analgesia that lasts one to two hours.

Since its introduction in the 1940's, reports of serious adverse sequelae, including injection of LA directly into the uterine arteries or fetal head, fetal death, and profound bradycardia, have resulted in modification of the injection technique and changes to the concentration and type of LA used. There are statements cautioning against employing this block in situations of uteroplacental insufficiency or non-reassuring FHR tracings. 
Overall, in current practice, the incidence of fetal bradycardia post block is about $15 \%,{ }^{68}$ with the onset beginning two to ten minutes after injection and the bradycardia lasting 15 to $30 \mathrm{~min}$. The exact etiology is unknown; however, a recent investigation comparing epidural with PCB using Doppler flow velocity waveforms of the maternal femoral and uterine, and umbilical and fetal middle cerebral arteries has shed some light on this phenomenon. ${ }^{69} \mathrm{PCB}$ was associated with a small but significant increase in uterine artery impedance, indicating uterine artery vasoconstriction. In this study, Apgar scores and umbilical arterial, and venous $\mathrm{pH}$ determinations were within the normal range in both groups.

\section{Neuraxial analgesia}

Spinal, epidural and combined spinal-epidural (CSE) techniques are used to administer opioids, LA, and other pain-modulating adjuvants.

\section{NEURAXIAL OPIOIDS}

Fetal bradycardia may develop following administration of intrathecal opioid, although its occurrence can follow any type of effective labour analgesia. ${ }^{70}$ While technique-specific etiologies can occur (for example, maternal hypotension or fetal LA toxicity), uterine hypertonus as the mechanism inciting the transient but profound drop in heart rate was first reported in $1994 . .^{71}$ This topic has been the subject of study ${ }^{72}$ and systematic review. ${ }^{73}$

Pain relief can affect uterine function. Hunter reported in 1962 that bilateral lumbar sympathetic block for first stage labour pain caused abnormal uterine contraction patterns to normalize and previously normal patterns to become hyperactive. ${ }^{74}$ Although there is likely more than one mechanism, the etiology is thought to be related to a change in the balance of circulating catecholamines occurring with the advent of analgesia, favouring $\alpha$ - over $\beta$-activation of smooth muscle receptors. ${ }^{40,75}$ Uterine muscle tone and vascular resistance increase as a result of the contractioninducing norepinephrine influence predominating over the contraction-relaxing epinephrine effect. FHR decreases because of a reduction in uteroplacental blood flow. The effect may be more pronounced in the face of oxytocin stimulation.

There is a temporal relationship between the speed of onset of labour pain relief and the appearance, if any, of the bradycardia. It occurs faster with spinal analgesia (less than ten minutes) and more slowly with epidural analgesia (15-30 min).$^{70}$ However, as Van de Velde et al. point out, speed of onset of labour pain relief cannot be the only factor at work. Nonreassuring FHR tracings did not occur after CSE using a mixture of bupivacaine and sufentanil $(1.5 \mu \mathrm{g})$ when compared to a larger dose of intrathecal sufentanil $(7.5 \mu \mathrm{g})$ alone, despite equally fast pain relief. ${ }^{72} \mathrm{~A}$ meta-analysis performed during a well-conducted systematic review of this topic revealed a significant increase in the risk of fetal bradycardia due to intrathecal opioid (odds ratio 1.8, 95\% confidence interval 1.0 to 3.1$).{ }^{73}$

The clinical implications are not obvious because the occurrence of FHR changes in response to labour analgesia has not prompted an increase in the rate of interventional delivery. ${ }^{73}$ The hypertonus usually lasts less than ten minutes and can be relieved by administration of a nitric oxide donor such as nitroglycerin $(50-100 \mu \mathrm{g} i \mathrm{v})$, or a $\beta_{2}$ agonist such as terbutaline (125-250 $\mathrm{gg} i \mathrm{v})$, in cases of prolonged fetal bradycardia. The observed changes in FHR have not correlated with observable clinical differences in neonatal outcome, including Apgar scores, cord $\mathrm{pH}$, prevalence of cord $\mathrm{pH}<7.15$, or admission rate to a neonatal intensive care unit. $^{72}$

\section{NEURAXIAL LA}

In general, when LA are used alone, concentrated solutions are required to afford pain relief. Since block density is dose dependent, the more concentrated the solution used, the greater the degree of motor block expected; this has been implicated in pelvic muscle relaxation-induced fetal malposition, maternal inability to push, and need for instrumental delivery. ${ }^{76}$ In a recent meta-analysis comparing randomized clinical trials of techniques using epidural LA alone with intrathecal opioid alone, ${ }^{77}$ the authors were unable to find sufficient information to comment on either similarities or differences in maternal and fetal outcomes. This study was accompanied by an insightful editorial that will assist readers to critically interpret the results of this and other systematic reviews and meta-analyses. ${ }^{78}$

\section{COMBINING OPIOIDS, LA, AND PAIN-RELIEVING} ADJUVANTS

When spinal, epidural, and CSE techniques involve combinations of pain-modulating drugs (sodium channel blocking agents, opioid-receptor agonists, $\alpha$ adrenergic agonists and/or acetylcholinesterase inhibitors) acting by different mechanisms, there is potential to afford analgesia with minimal motor blockade and other relevant side effects..$^{79,80}$

\section{Labour epidurals and outcome}

An erudite and interesting historical review of anesthesia for childbirth by Caton, Frölich, and Euliano provides the foundation for a discussion of the con- 
troversies and unresolved issues surrounding the influence of epidural analgesia on maternal outcomes that affect the fetus and newborn. ${ }^{81}$

There have been five systematic reviews ${ }^{54,82-85}$ comparing epidural to non-epidural analgesia methods. All focused in some manner on the clinical dilemma of balancing the alleviation of maternal pain with the possible increase in side effects and/or adverse outcomes for the mother and baby. Commentary about two of the reviews that were conducted in parallel is thought provoking. ${ }^{86}$

The following is a simplified summary of the information provided by the reviews:

1. Epidural solution concentration and technique varied tremendously over the 38-year time span covered. As a result, there were some qualitative differences in the effects of treatment (heterogeneity).

2. All reviewers concluded that there was insufficient evidence to support an increased incidence of Cesarean section with the use of epidural analgesia.

3. Data on babies were scanty, apart from gross measures such as Apgar scores and results of umbilical cord blood gas analysis. Some issues remained unproven; for instance the suggestion that "epidural analgesia is associated with less naloxone use and higher one-minute Apgar scores." No consistent picture emerged vis-à-vis the incidence of neonatal adverse effects associated with epidural. There was little evidence regarding the effects of epidural on fetal physiologic mechanisms.

4. Epidural analgesia was associated with (not necessarily a causal relationship):

i. longer second stage labour $(\sim 14 \mathrm{~min})$,

ii. more fetal malposition (occiput posterior),

iii. a higher rate of instrumental vaginal deliveries,

iv. maternal fever, and

v. increased use of oxytocin augmentation. This serves as an example of the association $v s$ causation debate. ${ }^{87}$

Halpern et al. noted ${ }^{82}$ that the quality of the clinical trials included in their review improved with time; all trials after 1995 reported outcomes with patients grouped by intent to treat. Analysis conducted in this way (i.e., by groups to which patients were randomized) is vital because women who choose epidurals differ demographically from those who choose other methods of labour analgesia. The former are more likely to be nulliparous, be admitted to hospital earlier in labour with higher fetal head positions, have slower rates of cervical dilation, bear heavier babies, and need oxytocin augmentation more frequently. All of these factors and degree of maternal pain independently predict the need for Cesarean delivery for dystocia. ${ }^{88}$
Obstetrical management practices have an important role to play in terms of the progress and outcome of labour. ${ }^{76}$ For instance, the presence of an epidural block may sometimes decrease the obstetrician's threshold for performing instrument-assisted deliveries, as well as for allowing instrument-assisted delivery for the purpose of teaching residents. Active management of labour (routine oxytocin augmentation and/or artificial rupture of membranes), delayed pushing in second stage, and promotion of ambulation have all been suggested as methods to reduce obstetric intervention and increase the number of spontaneous vaginal births. ${ }^{80}$

\section{Instrumental vaginal delivery}

Attempts at operative vaginal delivery (vacuum extraction or forceps) put the baby at risk of injury, including hemorrhagic morbidities such as subgaleal hematoma and cerebral hemorrhage.$^{89}$ Forceps use is also associated with facial nerve and brachial plexus injury. ${ }^{90}$ In a study comparing use of forceps and vacuum extractors, babies delivered by vacuum extraction showed a higher incidence of cephalohematomas, although need for resuscitation at birth, admission to a neonatal intensive care unit, and neonatal death rate was not different. ${ }^{91}$

Epidural analgesia has been associated with a higher rate of operative vaginal deliveries. ${ }^{82-85}$ Recently, the COMET study group ${ }^{92}$ showed that there was a decreased incidence of instrumental vaginal delivery when lower doses of medication (CSE, low dose LA plus opioid infusion) were used in labour compared to conventional doses of LA $(0.25 \%$ bupivacaine). The presumed mechanism is the preservation of motor tone and the bearing-down reflex. Mild neonatal depression necessitating neonatal resuscitation was more common among babies whose mothers were in the low dose LA plus opioid epidural infusion group, most likely due to the cumulative effect of the opioid over time. Neither the Apgar scores at five minutes nor the rates of admission to a neonatal care unit differed between groups.

Newer methods of epidural analgesia offer the best chance of spontaneous delivery with satisfactory pain control. ${ }^{93}$

\section{Delayed pushing}

The "Pushing Early or Pushing Late with Epidural" (PEOPLE) study, a multicentre, randomized, controlled trial, compared conventional early pushing commencing at full cervical dilation with pushing late, more than two hours after full dilation. Operative delivery was reduced with delayed pushing; however, 
umbilical arterial $\mathrm{pH}<7.10$ occurred more frequently among babies whose mothers were in the delayed pushing group. The two groups had similar rates of neonatal morbidity, including asphyxia. Protocols advocating delayed pushing result in longer second stages and increased incidences of maternal fever. ${ }^{94}$

\section{Maternal fever}

Mothers who receive an epidural are more likely to develop a fever during labour. ${ }^{95}$ The link between epidural analgesia, maternal fever, and the purported increase in neonatal septic work-ups is less clear. ${ }^{95-98}$ The concern is that babies are more likely to be treated with antibiotics since it is not currently possible to distinguish between maternal fever from infectious and noninfectious causes during labour. Many investigators believe the association of an epidural with fever is probably attributable to noninfectious causes, for example altered thermoregulation resulting from epidural analgesia. Neonates born to mothers who receive epidural analgesia do not have an increased risk of sepsis. ${ }^{76,95}$

\section{Breastfeeding}

A succinct and thorough review of this topic concludes that intrapartum epidural analgesia does not adversely affect a baby's or mother's ability to breastfeed. ${ }^{99}$ The most critical factors for breastfeeding success are support of, and education for, the mother.

\section{Forthcoming}

Examination of the fetal/newborn effects of maternal and fetal anesthesia for surgical procedures during pregnancy is presented in Part II, along with a discussion of anesthetic medications, techniques, and interventions related to surgical issues that arise for the mother and fetus during pregnancy and for the newborn during the early postpartum period. 


\section{PART II: ANESTHESIA FOR SURGERY}

Part II of this article deals with anesthetic medications, techniques, and interventions related to surgical issues that arise for the mother and fetus during pregnancy and for the newborn during the early postpartum period.

\section{Anesthetic techniques for Cesarean section: effects on the fetus and newborn \\ General anesthesia $(G A)$}

Given enough time, all medication administered to the mother crosses the placenta and enters the umbilical vein; therefore, gauging drug administration during the induction and maintenance phases of GA is necessary. An important factor affecting neonatal outcome is the elapsed time between the induction of anesthesia and clamping of the umbilical cord, as this represents the time of fetal exposure to maternally administered medication. A second factor is the time from uterine incision to delivery of the baby. A long incision to delivery time is associated with an increased incidence of fetal acidosis, presumably caused by uteroplacental vasoconstriction. If possible, induction to clamp time should be less than ten minutes and uterine incision to delivery time less than three minutes. ${ }^{100}$

The three determinants of placental transfer of drugs to the fetus include the physical-chemical properties of the drug, the characteristics of the maternal, placental, and fetal circulations, and placental anatomy and physiology. Fetal and neonatal pharmacological effects of anesthetic agents given to the mother during a Cesarean section conducted under GA depend on the amount of drug reaching the fetus. Estimating this is not an easy task.

There are difficulties associated with human in vivo studies of placental transfer during pregnancy. ${ }^{101}$ The feto-placental unit is inaccessible in situ and there are ethical considerations in conjunction with maternal and fetal safety. In vivo studies are most commonly performed at birth by collecting maternal venous and umbilical cord arterial and venous blood samples. It is difficult to draw conclusions based on one set of measurements. Likewise, the applicability of animal placentas as models for the human placenta is limited because the structure and function of the placenta is species-specific. Many studies of anesthetic pharmacology to date have been conducted using animal models. The alternative is to use a human ex vivo placental perfusion model. AlaKokko and colleagues make a strong case for the human placental perfusion model as the best method available for studying transplacental passage of drugs. ${ }^{101}$

It will take time to study anesthesia drugs using this methodology. The conclusions reached in most of the studies cited in the following discussion derive from animal and in vivo blood sampling data.

The induction agents used to initiate GA include sodium thiopental, methohexital, ketamine, propofol, and midazolam. Ketamine is usually reserved for situations involving maternal hemodynamic instability because it preserves sympathetic outflow. The others have been studied and compared. ${ }^{102-104}$ Midazolam and propofol have been associated with longer induction times, a lighter plane of maternal anesthesia (as measured by electroencephalogram), and lower Apgar scores. Sodium thiopental and methohexital share pharmacokinetic properties with thiamylal, another lipid soluble barbiturate that peaks in umbilical arterial plasma at three to five minutes and declines rapidly until 11 min. ${ }^{100,104}$ Induction to umbilical cord clamp times of approximately ten minutes coincide with declining fetal levels of these agents and therefore little neonatal depression.

Neuromuscular blocking drugs share a structural similarity, a quaternary ammonium ion, which slows but does not eliminate transfer of these drugs across the placenta. ${ }^{100}$ Succinylcholine is degraded so rapidly by plasma cholinesterase that virtually none reaches the fetus, whereas the percentage of nondepolarizing neuromuscular blocking drug (for example rocuronium, pancuronium, and atracurium) that crosses the placenta ranges from 7 to $22 \%$, depending on the drug. The literature is vague with respect to effects on the neonate. However, in the setting of high-dose nondepolarizing neuromuscular blockade (for example, EXIT procedures), it may be necessary to support neonatal ventilation for a period of time or to administer reversal agents.

The inhalation agents, desflurane and sevoflurane would be expected to cross the placenta and equilibrate in fetal tissues more rapidly than their more soluble counterparts (for example, isoflurane), potentially resulting in a more depressed neonate. Equally expected, however, once the newborn establishes ventilation, is that the lungs would excrete ("blow off") these relatively insoluble drugs more quickly. Desflurane is more pungent and irritating to the airway and may result in laryngospasm. This should be considered when suctioning the neonate whose mother has received desflurane. ${ }^{100}$ When compared with isoflurane $0.5 \%$, sevoflurane $1 \%$ (equianesthetic concentration) was found to produce similar maternal and neonatal results. ${ }^{105}$ Cord blood gases and Apgar scores were equivalent. Desflurane in a subanesthetic dose $(3 \%)$, mixed with $\mathrm{N}_{2} \mathrm{O}-\mathrm{O}_{2}$, was considered safe and effective for Cesarean section in healthy parturients when compared to enflurane $0.6 \%$. 
Higher doses of desflurane delayed time to sustained respiration in the newborn. ${ }^{106}$

\section{Regional anesthesia ( $R A$ )}

Under normal maternal and fetal conditions, skillfully conducted GA and RA are almost equivalent with respect to neonatal well-being. ${ }^{107,108}$ Nevertheless, given the risks to the mother and the association of lower Apgar scores with GA, RA for elective, and sometimes emergent, Cesarean section is preferred..$^{79,109-111}$ A compromised fetus may even benefit from anticipatory maternal epidural catheter placement in labour when there is a high risk of Cesarean section $^{112}$ or, primary epidural or spinal anesthesia for elective Cesarean section. ${ }^{110,113}$ RA results in less neonatal exposure to drugs (especially when the spinal technique is used), allows the mother and her partner to participate in the birth of their baby, and provides better maternal postoperative pain relief. ${ }^{114}$

For all the advantages of spinal anesthesia such as simplicity of technique, rapid onset, reduced risk of systemic toxicity, density of anesthetic block, and postoperative pain relief afforded by neuraxial morphine, the potential for hypotension with this technique poses the greatest threat to the mother and fetus. ${ }^{79}$ The incidence of hypotension is similar between epidural and spinal anesthesia, but occurs earlier and more rapidly with the spinal approach. Hypotension results from temporary sympathectomy, an inevitable but undesirable component of midthoracic blockade. Reduced preload (increased venous capacitance and pooling of blood volume in the splanchnic bed and lower extremities) and reduced afterload (decreased systemic vascular resistance) lower maternal mean arterial pressure (MAP), leading to nausea, lightheadedness and dysphoria, and reduced uteroplacental perfusion. When maternal MAP is maintained, maternal symptoms are averted and uteroplacental perfusion improves.

In their epidemiological study of 5,806 Cesarean deliveries, Mueller et al. concluded that fetal acidemia was significantly increased after spinal anesthesia, ${ }^{115}$ and maternal arterial hypotension was by far the most common problem encountered. The prevalence of fetal acidemia with RA for Cesarean section has been confirmed in another study. ${ }^{110}$ However, isolated acidemia does not correlate with Apgar scores and is a poor indicator of outcome. Low umbilical artery $\mathrm{pH}$ reflects both the respiratory and metabolic components of acidosis, whereas base excess reflects only the metabolic component. It is base excess that correlates with neonatal outcome, values more negative than -12 $\mathrm{mmol} \cdot \mathrm{L}^{-1}$ having an association with moderate to severe newborn encephalopathy. ${ }^{6}$ However, preven- tion of hypotension is advantageous to minimize any influence on neonatal acid-base status.

The routine measures used to maintain uteroplacental perfusion include left lateral tilt position, lower leg compressive stockings, and iv fluid loading. ${ }^{16,117}$ Vasopressor therapy is reserved for the treatment of hypotension. Prophylactic use of ephedrine in one study ${ }^{118}$ and therapeutic use in another ${ }^{110}$ possibly contributed to fetal acidemia. Likewise, ephedrine use was associated with lower umbilical arterial $\mathrm{pH}$ values when compared with phenylephrine in a systematic review. ${ }^{119}$ The literature is replete with debate regarding which vasopressor, a mixed $\alpha \beta$ agonist (for example, ephedrine) or a pure $\alpha$ agonist (for example, phenylephrine), would be more appropriate for the management of hypotension during spinal anesthesia for Cesarean delivery. ${ }^{120-123}$ The controversy revolves around the etiology of fetal acidemia: is it due to the metabolic effects of $\beta$-stimulation in the fetus or insufficient maintenance of uteroplacental perfusion by failure to reclaim sequestered blood from the splanchnic bed in order to augment preload? Regardless, the choice of a vasopressor drug is perhaps less important than the avoidance of hypotension. ${ }^{124}$

\section{Fetal effects of maternal oxygen administration}

Providing supplemental oxygen to the parturient during Cesarean section is common clinically, whether the procedure is elective, urgent, or emergent. ${ }^{125}$ This practice has been justified by the belief that raising the oxygen reserve of the mother is universally beneficial for the fetus. Since the advent of pulse oximetry, patients who may benefit from oxygen therapy are more easily identified, and clinicians can be more selective about administering oxygen therapeutically. For example, pulse oximetry readings obtained during elective Cesarean section conducted under spinal anesthesia showed that maternal saturation was well-maintained on room air, and administration of 35\% oxygen by facemask failed to significantly change umbilical vein $\mathrm{pH}$ or partial pressure of oxygen. ${ }^{126}$ This finding was further substantiated in a study by Cogliano et al. ${ }^{127}$

Oxygen given to the mother does not increase fetal oxygenation to the same extent because of utilization during intermediary placental metabolism. In comparison, neonatal oxygen therapy has the potential to raise newborn $\mathrm{PaO}_{2}$ substantially. There is a growing body of clinical and experimental evidence that seems to indicate the practice of routine supplemental oxygen during neonatal resuscitation may be injurious. ${ }^{128-130}$

Oxidative stress is implicated as a common underlying mechanism in several neonatal conditions, 
including necrotising enterocolitis, retinopathy of prematurity, periventricular leukomalacia, and chronic lung disease. ${ }^{131-133}$ It occurs when free radical generation exceeds the body's antioxidant defense mechanisms, and is not exclusive to newborns; free radicals and antioxidants also play a role in adult diseases. ${ }^{134,135}$ The interest in free radicals as harbingers of disease has prompted investigators to explore potential fetal effects of giving oxygen to mothers. Accordingly, the process of routine oxygen supplementation for healthy parturients undergoing elective Cesarean delivery with RA has been questioned. ${ }^{136}$

Free radicals have a brief life span, making their detection difficult. Therefore, studies investigating oxidative stress usually measure surrogate markers, namely products of the attack by free radicals on lipids, proteins and nucleotides. This methodology was used to examine the effect on the newborn of administering air or oxygen-enriched air to parturients undergoing elective Cesarean section. ${ }^{137}$ There was a clear difference between groups, with greater free radical activity in the babies born to mothers breathing oxygen-enriched air. The main site of free radical generation was the placenta, as evidenced by the higher concentration of free radicals in the umbilical vein compared to the artery. As Backe and Lyons point out, "At present, we have no means of linking free radical formation with neonatal outcome following elective Cesarean section. ....in a low risk situation such as [this], a favourable outcome is unlikely to be influenced by maternal hyperoxia". ${ }^{136}$ "The significance of [the Khaw et al. study] relates to the use of high inspired maternal oxygen fractions $(\geq 60 \%)$ for the delivery of compromised and premature [babies]". There are no published trials addressing maternal oxygen therapy for fetal distress. ${ }^{138}$

\section{Postpartum pain management}

This section is limited to pharmacological therapy and its implications for the breastfeeding mother. Breastfeeding calls for use of analgesic agents that are transferred minimally into breast milk and have little effect on the neonate. ${ }^{139}$

The act of breastfeeding results in milk production, secretion, let-down, and increased breast blood flow. Therefore, the timing of breastfeeding relative to drug administration influences the amount of drug that appears in the breast milk. Drug exposure can be minimized if the mother takes medication immediately after nursing or just before the baby is due to have a lengthy sleep, and uses short-acting medications. The neonatal dose of most medications obtained through breastfeeding is 1 to $2 \%$ of the maternal dose. ${ }^{140}$
Breast milk content also affects the extent of drug transfer from maternal plasma. For instance, lipid soluble drugs are less likely to accumulate in colostrum, which contains little fat. Colostrum has the same $\mathrm{pH}$ as maternal plasma, which is advantageous as far as narcotics are concerned. These weak bases are not sequestered in colostrum via ion trapping and therefore do not accumulate. Colostrum morphine concentrations have been measured during the first $48 \mathrm{hr}$ of post Cesarean $i v$ patient-controlled analgesia. ${ }^{141}$ The milk to maternal plasma ratio for morphine was less than one. Morphine was seen in very small concentrations in less than half of the milk samples. The authors concluded that the amount of drug likely to be transferred to the breastfed neonate was negligible. Only small amounts of colostrum are secreted during the first few postpartum days $\left(10-120 \mathrm{~mL} \cdot\right.$ day $\left.^{-1}\right)$, so newborn exposure from volume is limited. Ultimately, the concentration of drug in the baby's plasma is more important than the concentration of the drug in colostrum or breast milk. This depends on absorption across the gastrointestinal tract, the volume of distribution, and the extent of metabolism and excretion in the newborn. Little is known about the bioavailability of analgesics and their metabolites because of ethical issues involved in repeated blood sampling from babies.

Milk composition continues to change over the first ten days after birth. There is a gradual increase in fat and lactose content and a reduction in protein and $\mathrm{pH}$. By day ten postpartum, factors such as high lipid solubility, low molecular weight, minimal protein binding, and the un-ionized state facilitate secretion of medications into mature breast milk. ${ }^{142}$ Women who breastfeed and require GA for surgery are usually counseled to feed their baby before the surgery and temporarily interrupt feeding postoperatively by wasting the first milk sample (express with a breast pump and discard). After that, if the mother feels well enough and there are no surgical contraindications, she is encouraged to resume feeding. Most anesthetics are rapidly cleared from the mother; some authors argue that no portion of human milk need be wasted. ${ }^{142}$

The American Academy of Pediatrics (AAP) published a statement on drug transfer into human milk and possible effects on the infant or on lactation in order to assist prescribing practices. ${ }^{143}$ The AAP considers acetaminophen, most non-steroidal anti-inflammatory drugs, and morphine compatible with breastfeeding.

\section{Surgery during pregnancy}

Urgent surgery during pregnancy requires modification of anesthetic and surgical approaches to address 
the safety of the mother and her fetus. ${ }^{144-146}$ Anesthetic considerations include:

1. Management of maternal risk factors resulting from physiological adaptation to the demands of a growing fetus and ongoing support of the placental unit;

2. Maintenance of the pregnant state;

3. Optimization of uteroplacental perfusion and fetal oxygenation, and maintenance of a stable intrauterine environment;

4. Attention to the direct and indirect actions of maternally administered medications on fetal wellbeing.

The choice of anesthetic technique is guided by maternal indications, taking into account the site and nature of surgery. Efforts are made to reduce fetal drug exposure and, with reassurance, allay maternal anxiety. Most abdominal procedures, however, require GA to provide sufficient muscle relaxation to facilitate surgical exposure.

Approximately $2 \%$ of pregnant women require surgery during pregnancy. ${ }^{145}$ The procedure may be directly related (for example, cervical cerclage), indirectly related (for example, ovarian cystectomy), or unrelated (for example, appendectomy) to pregnancy. Semi-elective procedures should be delayed until the second trimester. Surgery at this time avoids the vulnerable period of organogenesis ( $15-60$ days gestation) and the technical difficulties of maneuvering around a large, gravid uterus or managing the maternal airway in an advanced stage of pregnancy. Special techniques, including laparoscopy, cardiopulmonary bypass, transplantation, and induced hypothermia have all been performed safely during pregnancy. ${ }^{144}$

Premature labour represents the greatest risk to the fetus in the perioperative period. Neonatal mortality in the developed world is approximately $50 \%$ at 25 weeks, dropping to about $10 \%$ at 30 weeks. ${ }^{147}$ Postponing surgery during this period of rapid fetal maturation should weigh the advantages to the fetus against the hazards that delay poses to the mother. There is no evidence to suggest that any anesthetic agent, dose, or technique influences the risk of preterm labour. ${ }^{145}$ Rather, it is more likely to be related to the surgery itself, manipulation of the uterus, or the underlying condition of the mother (for example, infection). The more advanced the pregnancy, the greater the probability of uterine irritability. Certain medications can be used as part of the anesthetic technique to promote uterine quiescence (for example, magnesium sulfate, inhalational anesthetic agents, or $\beta_{2}$ agonists) and surgical strategies can be employed to avoid handling the uterus. Intravenous, sublingual or transcutaneous administration of nitroglycerin is usually reserved for uterine relaxation during brief procedures, or to manage refractory uterine activity. ${ }^{148}$

The decision to monitor the fetus during surgery necessitates that someone be available for ongoing interpretation of fetal well-being, and that there be a plan for intervention should fetal distress be diagnosed or suspected. Indicators of fetal distress are often indistinct because technical limitations at various gestational ages eclipse data acquisition, and FHR variability is reduced or eliminated by certain anesthetic drugs. Intervention may include delivery, reassessment of anesthetic depth, or a more aggressive approach to maximize uterine blood flow, tocolysis, and/or maternal oxygenation. ${ }^{144}$ If delivery of the fetus is planned to occur at the same time as surgery, a coordinated team approach involving anesthesia, obstetrics, surgery, nursing, respiratory therapy, and neonatology is vital.

The well-being of the fetus is dependent on the adequacy of the maternal blood supply to the placenta, which is mainly derived from the uterine arteries. ${ }^{116}$ The uterine vascular bed is a low resistance system, not capable of further dilatation, and devoid of autoregulation. Therefore, placental blood flow varies directly with net perfusion pressure (uterine artery pressure uterine venous pressure) across the intervillous space and inversely with uterine vascular resistance. When faced with maternal hypotension, in order to preserve uteroplacental perfusion in a "pressure-passive" system, a more aggressive approach to management (rapid fluid loading, vasopressor therapy, Trendelenburg and left lateral positioning) is required compared to strategies for the non-pregnant patient. ${ }^{146}$ Hypotension may be due to many different etiologies but commonly results from aortocaval compression in the supine position, general or high spinal anesthesia, or hemorrhage. Maintaining homeostasis in the intra-uterine environment also requires attention to maternal oxygenation, temperature, and acidbase balance (respiratory and metabolic).

Most anesthetic agents are not known to be teratogens. When evaluating the possibility of teratogenicity from maternally administered anesthetic medications, points to be considered include: ${ }^{140,144}$

1. The incidence of congenital anomalies in the developed world is $3 \%$;

2. Human teratogenicity studies are impossible to perform for ethical reasons;

3. Extrapolation from animal studies may not be valid;

4. Hypoxemia and hypotension cause physiological derangement that may be teratogenic. 
Drugs that are usually avoided during anesthesia for long surgical procedures in early pregnancy include $\mathrm{N}_{2} \mathrm{O}$ and benzodiazepines. $\mathrm{N}_{2} \mathrm{O}$ is avoided because it causes oxidation of vitamin $\mathrm{B} 12$, rendering it incapable of functioning as a co-factor for methionine synthetase, an enzyme necessary for DNA synthesis in humans. Benzodiazepines are avoided because epidemiological studies have shown a link to the development of congenital inguinal hernia. ${ }^{140}$

Postoperative pain management may include plexus blocks or epidurals, where appropriate, in order to limit fetal exposure to drugs. Opioids and acetaminophen are used widely. Prolonged use of nonsteroidal anti-inflammatory drugs is avoided due to concerns about premature constriction of the ductus arteriosus and development of oligohydramnios.

\section{Fetal surgery}

Fetal surgery is defined as "the performance of procedures on the fetus or placenta designed to alter the natural history of a fetal disease that is diagnosed in utero". ${ }^{149}$ Surgery can vary from minimally invasive percutaneous procedures, facilitated by local, spinal, or epidural anesthesia, to direct fetal operations following a hysterotomy incision. The latter requires maternal GA and attention to the possibility of inflicting pain on the fetus. ${ }^{150}$ Anesthetic considerations are identical to those for non-obstetric surgery during pregnancy although the fetus is the primary patient in these circumstances.

Fetal sedation by placental transfer of maternally administered medication is not reliable and does not ensure an anesthetized or immobile fetus. Given enough time, and subject to their individual solubilities, the inhalation anesthetic agents used for maternal GA and uterine relaxation equilibrate in fetal tissues. Deep maternal inhalation anesthesia may result in progressive fetal acidosis by an uncertain mechanism. Fetal blood pressure, heart rate, oxygen saturation, and base excess can decrease due to direct impairment of fetal myocardial contractility, redistribution of fetal blood flow, or changes in uterine perfusion. Fetal distress and response to maneuvers can be recognized and managed by measuring heart rate, blood pressure, and umbilical blood flow, and by monitoring $\mathrm{pH}$, $\mathrm{pCO}_{2}, \mathrm{pO}_{2}$, base deficit, glucose, and electrolytes. Vascular access facilitates this and, the administration of fluid, blood products, and/or drugs. ${ }^{151}$

Additional fetal anesthesia can be provided by direct $i m$ or intravascular (via the umbilical vein) administration of opioids and neuromuscular blocking agents. Pancuronium is often chosen for fetal paralysis because of its long duration and vagolytic properties, which help elevate the FHR and maintain cardiac output. Fentanyl, in relatively large doses (12.5-25 $\mu \mathrm{g} \cdot \mathrm{kg}^{-1}$ estimated fetal weight), attenuates the autonomic and hormonal stress response during potentially painful procedures. ${ }^{48,151}$ In the face of intense uterine tocolysis, maintenance of maternal blood pressure may require concomitant vasopressor therapy.

The Ex Utero Intrapartum Treatment (EXIT) procedure was developed for fetuses that have a predictably compromised airway, either because of prior in utero surgery (for example, to treat congenital diaphragmatic hernia) or due to an obstructing mass, such as cystic hygroma or thyroid goiter. Delivery occurs by planned Cesarean section with an anesthetic approach that maintains uterine relaxation. A hysterotomy incision is made with a device that limits uterine bleeding, and the fetus is partially delivery through the incision. The surgeon performs laryngoscopy or tracheotomy and secures the airway (endotracheal tube or tracheotomy tube) while the fetus is still attached to the umbilical cord and maintained on uteroplacental perfusion. Attention is paid to avoiding fetal hypothermia. The fetal lungs are expanded and surfactant administered if the infant is premature. The cord is then clamped and the remainder of the Cesarean section proceeds as usual. Fetal well-being and operating conditions have been maintained for up to two hours during EXIT procedures. ${ }^{149,151}$

Whether the fetus feels pain, and from what gestational age, has been the subject of vigorous debate. ${ }^{150,152,153}$ Prior to 22 weeks, the fetus does not have the neuroanatomic pathways in place to feel pain; between 22 to 26 weeks, thalamo-cortical fibres, considered to be crucial for nociception, are forming; and after 26 weeks, the fetus has the necessary neurological development to feel pain. Investigators have used surrogate endpoints, including fetal "reflex" movement away from, and the biochemical stress response to, noxious stimuli, in an attempt to define markers of pain. Hormonal and circulatory stress responses to invasive procedures are observed by 20 weeks. ${ }^{45-49}$

Further definition of the neuroanatomical and neurophysiological maturation of sensory pathways involved in pain transmission in the human fetus may provide more direct information about the fetal pain experience.

\section{Resuscitation during pregnancy Intra-uterine resuscitation of the compromised fetus} The term "non-reassuring intrapartum surveillance" is used to identify a state of progressive fetal asphyxia with hypoxia and acidosis, which, if not corrected, results in decompensation and permanent organ dam- 
age. It is diagnosed or suspected when characteristically "abnormal" features emerge in one or more of the tests used to evaluate fetal well-being. The term "non-reassuring intrapartum surveillance" has replaced the term "fetal distress".

Intra-uterine resuscitation consists of a series of maneuvers designed to reverse treatable causes of fetal asphyxia, restore fetal oxygenation, and correct fetal acidosis. These maneuvers are fundamental to the practice of obstetric anesthesia and are summarized, using an evidence-based template, by Thurlow and Kinsella. ${ }^{154}$ The circumstances surrounding the onset of fetal distress direct the order of application and determine which aspects of intra-uterine resuscitation are appropriate for a particular patient. The goals and measures are:

1. Increase blood flow to the placenta

i. treat maternal hypotension aggressively by administering a non-glucose containing crystalloid/colloid $i v$ fluid bolus, stopping the epidural infusion, and giving vasopressor therapy,

ii. alleviate aortocaval compression by changing the mother's position until an improvement in FHR occurs (left lateral, followed by right lateral, and finally, knee chest position),

iii. reverse uterine artery vasoconstriction induced by hypocapnia from maternal hyperventilation by managing pain and providing verbal reassurance.

2. Relax uterine muscle

i. stop oxytocin infusion,

ii. administer a tocolytic such as nitroglycerin 50-100 $\mu \mathrm{g} i \mathrm{v}$.

3. Increase fetal oxygenation

i. administer $100 \%$ oxygen to the mother by face mask,

ii. relieve umbilical cord compression by changing the mother's position or, if oligohydramnios is present, consider amnioinfusion.

4. Rule out umbilical cord prolapse or, if present, provide manual elevation of the presenting part per vagina, maintaining warmth and moisture for the cord until emergent delivery.

5. Confirm fetal asphyxia by an alternate test.

6. Prepare for emergent delivery.

\section{Maternal cardiac arrest}

The management of cardiac arrest in pregnancy is outlined in the Guidelines 2000 for Cardiopulmonary Resuscitation and Emergency Cardiovascular Care. ${ }^{155}$ Acute Cardiac Life Support protocols are modified in pregnancy, but the standard adult algorithms for medication, intubation, and defibrillation still apply.
The key to resuscitation of the fetus is resuscitation of the mother. Relief of aortocaval compression is paramount. Chest compressions are performed higher on the sternum to adjust for the shift of abdominal contents toward the head. Consideration of arrest etiologies unique to pregnancy (for example, amniotic fluid embolism) and diagnoses exacerbated by the physiological changes of pregnancy (for example, peripartum cardiomyopathy) is important if response to resuscitative efforts is lacking. All medication infusions such as magnesium sulfate, oxytocin, or epidural are discontinued and early intubation is encouraged to reduce the risk of aspiration. Fetal surveillance monitors (for example, scalp electrode lead) must be discontinued prior to defibrillation. The decision to perform open-chest cardiac massage or emergent Cesarean section should occur earlier rather than later if circulation is not restored by usual measures. Perimortem Cesarean section has the highest chance of improving outcome for both mother and baby when uterine size is $>20$ weeks (some would say $>24$ weeks) and delivery occurs within five minutes of the onset of the arrest. ${ }^{156}$

\section{Perimortem Cesarean section}

Perimortem Cesarean section refers to emergent operative delivery of the fetus through a midline, classical uterine incision in situations where the mother is moribund or pulseless and is being actively resuscitated. Emptying the uterine cavity increases maternal cardiac output (contraction of the myometrium results in autotransfusion of blood previously directed to the uterus and improved preload secondary to relief of inferior vena cava compression) and lung volume and, makes it easier to perform effective chest compressions.

Accurate data regarding the incidence and outcome of this procedure for the mother or the neonate are difficult to obtain. For example, the British Confidential Enquiry does not report deliveries where the mother has been successfully resuscitated. ${ }^{157}$ There have been several case reports of expedient Cesarean delivery where both mother and baby have survived fully intact. Perimortem Cesarean section is an established part of the resuscitation process in nearterm pregnant women. ${ }^{155}$ In the largest series to date, Katz et al. reviewed the literature from 1900 to 1985 for papers where time from cardiopulmonary arrest to delivery was listed. ${ }^{158}$ Most fetal survivors were delivered within five minutes. The general consensus is that the likelihood of perimortem Cesarean section resulting in a living and neurologically normal baby is related to the interval between onset of maternal cardiac 
arrest and delivery. Also, the chances of normal survival are good following delivery if the fetus lives past the first few days. ${ }^{157}$ For this technique to be an option, it must be considered in the context of immediately available staff and equipment to perform the Cesarean section, and staff and equipment to conduct the neonatal resuscitation.

\section{Conclusion}

The well-being of the fetus and newborn is a major criterion for evaluating the obstetric and anesthetic management of pregnant women. Many tools exist to assist with this determination for the fetus, whereas few are available to evaluate the newborn.

Administration of analgesia/anesthesia to the mother has the potential to impact upon the fetus/ newborn. The ideal agent(s) and/or technique(s) would be efficacious and safe for the mother, not imperil the fetus in utero, improve the course of a dysfunctional labour, not interfere with the progress of labour, and provide satisfactory conditions for delivery, permit early mother-baby interaction, and have no short- or long-term impact on neonatal outcome. The challenge for the anesthesiologist is to balance the needs of the mother and the fetus/newborn while being flexible enough to modify or change the approach as circumstances dictate.

\section{Acknowledgement}

My thanks to the staff at the Neil John Maclean Health Sciences Library, University of Manitoba and on-line search system developers everywhere for helping to simplify the process of identifying and retrieving journal articles.

\section{References}

1 Caton D. The history of obstetric anesthesia. In: Chestnut DH (Ed.). Obstetric Anesthesia, Principles and Practice, 2nd ed. New York: Mosby; 1999: 1-13.

2 Apgar $V$. A proposal for a new method of evaluation of the newborn infant. Curr Res Anesth Analg 1953; 32: 260-7.

3 Papile L. The Apgar score in the 21st century (Editorial). N Engl J Med 2001; 344: 519-20.

4 Thorp JA, Rushing RS. Umbilical cord blood gas analysis. Obstet Gynecol Clin North Am 1999; 26: 695-709.

5 Helwig JT, Parer JT, Kilpatrick SJ, Laros RK Jr. Umbilical cord blood acid-base state: what is normal? Am J Obstet Gynecol 1996; 174: 1807-14.

6 Ross $M G$, Gala $R$. Use of umbilical artery base excess: algorithm for the timing of hypoxic injury. Am J Obstet Gynecol 2002; 187: 1-9.

\section{National Committee for Clinical Laboratory} Standards. Blood gas pre-analytical considerations: specimen collection, calibration and controls, approved guideline. NCCLS (Villanova PA) Document C27-A 1993; 13: 1-45.

8 Yoon BH, Kim SW. The effect of labor on the normal values of umbilical blood acid-base status. Acta Obstet Gynecol Scand 1994; 73: 555-61.

9 Reynolds F, Sharma SK, Seed PT. Analgesia in labour and fetal acid-base balance: a meta-analysis comparing epidural with systemic opioid analgesia. BJOG 2002; 109: 1344-53.

10 Als H, Tronick E, Lester BM, et al. The Brazelton Neonatal Behavioral Assessment Scale (BNBAS). J Abnorm Child Psychol 1977; 5: 215-31.

11 Scanlon JW, Brown WU Jr, Weiss JB, Alper MH. Neurobehavioural responses of newborn infants after maternal epidural anesthesia. Anesthesiology 1974; 40: 121-8.

12 Amiel-Tison C, Barrier G, Shnider SM, Levinson G, Hughes SC, Stefani SJ. A new neurologic and adaptive capacity scoring system for evaluating obstetric medications in full-term newborns. Anesthesiology 1982; 56: 340-50.

13 Brockhurst NJ, Littleford JA, Halpern SH. The neurologic and adaptive capacity score. A systematic review of its use in obstetric anesthesia research. Anesthesiology 2000; 92: 237-46.

14 Halpern SH, Littleford JA, Brockhurst NJ, Youngs PJ, Malik N, Owen HC. The neurologic and adaptive capacity score is not a reliable method of newborn evaluation. Anesthesiology 2001; 94: 958-62.

15 Liston R, Crane J. Fetal health surveillance in labour, part 1. SOGC Clinical Practice Guidelines No. 112, March 2002. Available from: http://www.sogc.org/SOGCnet/sogc_docs/common/guide/library_e.shtml\#obstetrics (accessed May 6, 2003).

16 Liston R, Crane J. Fetal health surveillance in labour, part 2. SOGC Clinical Practice Guidelines No. 112, April 2002. Available from: http://www.sogc.org/SOGCnet/sogc_docs/common/guide/library_e.shtml\#obstetrics (accessed May 6, 2003).

17 Thacker SB, Stroup D, Chang M. Continuous electronic heart rate monitoring for fetal assessment during labor. (Cochrane Review). In: The Cochrane Library, Issue 1, 2003. Oxford: Update Software (CD-ROM).

18 Dawes G, Meir YJ, Mandruzzato GP. Computerized evaluation of fetal heart rate patterns. J Perinat Med 1994; 22: 491-9.

19 Neilson JP, Mistry RT. Fetal electrocardiogram plus 
heart rate recording for fetal monitoring during labour. (Cochrane Review). In: The Cochrane Library, Issue 1, 2003. Oxford: Update Software (CD-ROM).

20 Norén H, Ameer-Wåblin I, Hagberg H, et al. Fetal electrocardiography in labor and neonatal outcome: data from the Swedish randomized controlled trial on intrapartum fetal monitoring. Am J Obstet Gynecol 2003; 188: 183-92.

21 Solt I, Ganadry S, Weiner Z. The effect of meperidine and promethazine on fetal heart rate indices during the active phase of labor. Isr Med Assoc J 2002; 4: 178-80.

22 Hoffman III CT, Guzman ER, Richardson MJ, Vintzileos A, Houlihan C, Benito C. Effects of narcotic and non-narcotic continuous epidural anesthesia on intrapartum fetal heart rate tracings as measured by computer analysis. J Matern Fetal Med 1997; 6: 200-5.

23 St. Amant MS, Koffel BL, Malinow AM. The effects of epidural opioids on fetal heart rate variability when coadministered with $0.25 \%$ bupivacaine for labor analgesia. Am J Perinatol 1998; 15: 351-6.

24 Manning FA. Fetal biophysical profile: a critical appraisal. Clin Obstet Gynecol 2002; 45: 975-85.

25 Manning FA, Snijders R, Harman CR, Nicolaides K, Menticoglou S, Morrison I. Fetal biophysical profile score. VI. Correlation with antepartum umbilical venous fetal pH. Am J Obstet Gynecol 1993; 169: 755-63.

26 Farrell T, Owen P, Harrold A. Fetal movements following intrapartum maternal opiate administration. Clin Exp Obst Gyn 1996; 23: 144-6.

27 Kopecky EA, Ryan ML, Barrett JF, et al. Fetal response to maternally administered morphine. Am J Obstet Gynecol 2000; 183: 424-30.

28 Smith CV, Rayburn WF, Allen KV, Bane TM, Livezey $G T$. Influence of intravenous fentanyl on fetal biophysical parameters during labor. J Matern Fetal Med 1996; 5: 89-92.

29 Dildy GA. Fetal pulse oximetry: current issues. J Perinat Med 2001; 29: 5-13.

30 East CE, Colditz PB, Begg LM, Brennecke SP. Update on intrapartum fetal pulse oximetry. Aust N Z J Obstet Gynaecol 2002; 42: 119-24.

31 Carbonne B, Langer B, Goffinet F, et al. Multicenter study on the clinical value of fetal pulse oximetry. II. Compared predictive values of pulse oximetry and fetal blood analysis. Am J Obstet Gynecol 1997; 177: 593-8.

32 Paternoster DM, Micaglio M, Tambuscio B, Bracciante $R$, Chiarenza $A$. The effects of epidural analgesia and uterine contractions on fetal oxygen saturation during the first stage of labour. Int J Obstet Anesthesia 2001; 10: 103-7.

33 East CE, Colditz PB. Effect of maternal epidural analgesia on fetal intrapartum oxygen saturation. Am J Perinatol 2002; 19: 119-26.

34 Harman CR, Baschat AA. Comprehensive assessment of fetal wellbeing: which Doppler tests should be performed? Curr Opin Obstet Gynecol 2003; 15: 147-57.

35 Ramos-Santos E, Devoe LD, Wakefield ML, Sherline $D M$, Metheny WP. The effects of epidural anesthesia on the Doppler velocimetry of umbilical and uterine arteries in normal and hypertensive patients during active term labor. Obstet Gynecol 1991; 77: 20-5.

36 Erkinjuntti M, Vaabtoranta K, Alihanka J, Kero P. Use of the SCSB method for monitoring of respiration, body movements and ballistocardiogram in infants. Early Hum Dev 1984; 9: 119-26.

37 Nikkola EM, Kirjavainen TT, Ekblad UU, Kero PO, Salonen MA. Postnatal adaptation after caesarean section or vaginal delivery, studied with the staticcharge-sensitive bed. Acta Paediatr 2002; 91: 927-33.

38 Nikkola EM, Jahnukainen TJ, Ekblad UU, Kero PO, Salonen $M A$. Neonatal monitoring after maternal fentanyl analgesia in labor. J Clin Monit Comput 2000; 16: 597-608.

39 Brownridge P. The nature and consequences of childbirth pain. Eur J Obstet Gynecol Reprod Biol 1995; 59(Suppl.): S9-15.

40 Neumark J, Hammerle AF, Biegelmayer C. Effects of epidural analgesia on plasma catecholamines and cortisol in parturition. Acta Anaesthesiol Scand 1985; 29: 555-9.

41 Lowe NK. The nature of labor pain. Am J Obstet Gynecol 2002; 186: S16-24.

42 Kubli M, Scrutton MJ, Seed PT, O'Sullivan G. An evaluation of isotonic "sport drinks" during labor. Anesth Analg 2002; 94: 404-8.

43 May AE, Elton CD. The effects of pain and its management on mother and fetus. Bailliere's Clin Obstet Gynaecol 1998; 12: 423-41.

44 Kitzinger $S$. Controversies: Natural childbirth is inappropriate in a modern world - opposer position. Int J Obstet Anesthesia 2002; 11: 28-32.

45 Bhutta AT, Garg S, Rovnaghi CR. Fetal response to intra-uterine needling: is it pain? Does it matter? Pediatric Research 2002; 51: 2.

46 Glover V, Fisk NM. Fetal pain: implications for research and practice. Br J Obstet Gynaecol 1999; 106: 881-6.

47 Gitau R, Fisk NM, Teixeira JM, Cameron A, Glover $V$. Fetal hypothalamic-pituitary-adrenal stress respons- 
es to invasive procedures are independent of maternal responses. J Clin Endocrinol Metab 2001; 86: 104-9.

48 Fisk NM, Gitan R, Teixeira JM, Giannakoulopoulos X, Cameron AD, Glover VA. Effect of direct fetal opioid analgesia on fetal hormonal and hemodynamic stress response to intrauterine needling. Anesthesiology 2001; 95: 828-35.

49 Anand KJ, Maze M. Fetuses, fentanyl, and the stress response. Signals from the beginnings of pain? (Editorial). Anesthesiology 2001; 95: 823-5.

50 Simkin PP, O'Hara MA. Nonpharmacologic relief of pain during labor: systematic reviews of five methods. Am J Obstet Gynecol 2002; 186: S131-59.

51 Fenwick L, Simkin P. Maternal positioning to prevent or alleviate dystocia in labor. Clin Obstet Gynecol 1987; 30: 83-9.

52 Bailey PL, Egan TD, Stanley TH. Intravenous opioid anesthetics. In: Miller RD (Ed.). Anesthesia, 5th ed, vol 1. Philadelphia: Churchill Livingstone; 2000: 273-376.

53 Ala-Kokko T, Vähäkangas K, Pelkonen O. Placental function and principles of drug transfer. Acta Anaesthesiol Scand 1993; 37: 47-9.

54 Bricker L, Lavender T. Parenteral opioids for labor pain relief: a systematic review. Am J Obstet Gynecol 2002; 186: S94-109.

55 Tomson G, Garle RI, Thalme B, Nisell H, Nylund L, Rane $A$. Maternal kinetics and transplacental passage of pethidine during labour. Br J Clin Pharmacol 1982; 13: 653-9.

56 Kubnert BR, Kubnert PM, Philipson EH, Syracuse $C D$. Disposition of meperidine and normeperidine following multiple doses during labor. II. Fetus and neonate. Am J Obstet Gynecol 1985; 151: 410-5.

57 Craft JB Jr, Coaldrake LA, Bolan JC, et al. Placental passage and uterine effects of fentanyl. Anesth Analg 1983; 62: 894-8.

58 Rayburn WF, Smith CV, Parriott JE, Woods RE. Randomized comparison of meperidine and fentanyl during labor. Obstet Gynecol 1989; 74: 604-6.

59 Krishna BR, Zakowski MI, Grant GJ. Sufentanil transfer in the human placenta during in vitro perfusion. Can J Anaesth 1997; 44: 996-1001.

60 Kan RE, Hughes SC, Rosen MA, Kessin C, Preston $P G$, Lobo EP. Intravenous remifentanil. Placental transfer, maternal and neonatal effects. Anesthesiology 1998; 88: 1467-74.

61 Volmanen P, Akural EI, Raudaskoski T, Alabubta S. Remifentanil in obstetric analgesia: a dose finding study. Anesth Analg 2002; 94: 913-7.

62 Saunders TA, Glass PS. A trial of labor for remifentanil (Editorial). Anesth Analg 2002; 94: 771-4.

63 Blair JM, Hill DA, Fee JP. Patient-controlled analge- sia for labour using remifentanil: a feasibility study. $\mathrm{Br}$ J Anaesth 2001; 87: 415-20.

64 Mc Guire W, Fowlie PW. Naloxone for narcoticexposed newborn infants (Cochrane Review). In: The Cochrane Library, Issue 1, 2003. Oxford: Update Software (CD-ROM).

65 Nicolle E, Devillier P, Delanoy B, Durand C, Bessard $G$. Therapeutic monitoring of nalbuphine: transplacental transfer and estimated pharmacokinetics in the neonate. Eur J Clin Pharmacol 1996; 49: 485-9.

66 Schindler SD, Eder H, Ortner R, Rohrmeister K, Langer $M$, Fischer $G$. Neonatal outcome following buprenorphine maintenance during conception and throughout pregnancy. Addiction 2003; 98: 103-10.

67 Rosen MA. Nitrous oxide for relief of labor pain: a systematic review. Am J Obstet Gynecol 2002; 186: S110-26.

68 Rosen MA. Paracervical block for labor analgesia: a brief historic review. Am J Obstet Gynecol 2002; 186: S127-30.

69 Manninen T, Aantaa R, Salonen M, Pirbonen J, Palo $P$. A comparison of the hemodynamic effects of paracervical block and epidural anesthesia for labor analgesia. Acta Anaesthesiol Scand 2000; 44: 441-5.

70 Norris MC. Intrathecal opioids and fetal bradycardia: is there a link? Int J Obstet Anesthesia 2000; 9: 264-9.

71 Clarke VT, Smiley RM, Finster M. Uterine hyperactivity after intrathecal injection of fentanyl for analgesia during labor: a cause of fetal bradycardia? (Letter). Anesthesiology 1994; 81: 1083.

72 Van de Velde M, Vercauteren M, Vandermeersch E. Fetal heart rate abnormalities after regional analgesia for labor pain: the effect of intrathecal opioids. Reg Anesth Pain Med 2001; 26: 257-62.

73 Mardirosoff C, Dumont L, Boulvain M, Tramer MR. Fetal bradycardia due to intrathecal opioids for labour analgesia: a systematic review. BJOG 2002; 109 : 274-81.

74 Hunter CA Jr. Uterine motility studies during labor. Observations on bilateral sympathetic nerve block in the normal and abnormal first stage of labor. Am J Obstet Gynecol 1963; 85: 681-6.

75 Segal S, Csavoy AN, Datta $S$. The tocolytic effect of catecholamines in the gravid rat uterus. Anesth Analg 1998; 87: 864-9.

76 Eltzschig HK, Lieberman ES, Camann WR. Regional anesthesia and analgesia for labor and delivery. $\mathrm{N}$ Engl J Med 2003; 348: 319-32.

77 Bucklin BA, Chestnut DH, Hawkins JL. Intrathecal opioids versus epidural local anesthetics for labor analgesia: a meta-analysis. Reg Anesth Pain Med 2002; 27: 23-30. 
78 Halpern S. Why meta-analysis? (Editorial). Reg Anesth Pain Med 2002; 27: 3-5.

79 Richardson $M G$. Regional anesthesia for obstetrics. Anesthesiol Clin North America 2000; 18: 383-406.

80 Mayberry LJ, Clemmens D, De A. Epidural analgesia side effects, co-interventions, and care of women during childbirth: a systematic review. Am J Obstet Gynecol 2002; 186: S81-93.

81 Caton D, Frölich MA, Euliano TY. Anesthesia for childbirth: controversy and change. Am J Obstet Gynecol 2002; 186: S25-30.

82 Halpern SH, Leighton BL, Ohlsson A, Barrett JF, Rice $A$. Effect of epidural vs parenteral opioid analgesia on the progress of labor. A meta-analysis. JAMA 1998; 280: 2105-10.

83 Howell CJ. Epidural versus non-epidural analgesia for pain relief in labour (Cochrane Review). In: The Cochrane Library, Issue 1, 2003. Oxford: Update Software (CD-ROM).

84 Leighton BL, Halpern SH. The effects of epidural analgesia on labor, maternal, and neonatal outcomes: a systematic review. Am J Obstet Gynecol 2002; 186: S69-77.

85 Lieberman E, O'Donoghue C. Unintended effects of epidural analgesia during labor: a systematic review. Am J Obstet Gynecol 2002; 186: S31-68.

86 Thacker SB, Stroup DF. Methods and interpretation in systematic reviews: commentary on two parallel reviews of epidural analgesia during labor. Am J Obstet Gynecol 2002; 186: S78-80.

87 Breen TW. Databases and obstetric anesthesia research: opportunity and limitations. Int J Obstet Anesthesia 2003; 12: 1-3.

88 Segal BS, Birnbach DJ. Epidurals and cesarean deliveries: a new look at an old problem (Editorial). Anesth Analg 2000; 9: 775-7.

89 Benedetti TJ. Birth injury and method of delivery (Editorial). N Engl J Med 1999; 341: 1758-9.

90 Towner D, Castro MA, Eby-Wilkens E, Gilbert WM. Effect of mode of delivery in nulliparous women on neonatal intracranial injury. N Engl J Med 1999; 341: 1709-14.

91 Weerasekera DS, Premaratne S. A randomised prospective trial of the obstetric forceps versus vacuum extraction using defined criteria. J Obstet Gynaecol 2002; 22: 344-5.

92 Comparative Obstetric Mobile Epidural Trial (COMET) Study Group UK. Effect of low-dose mobile versus traditional epidural techniques on mode of delivery: a randomised controlled trial. Lancet 2001; 358: 19-23.

93 Thornton JG, Capogna G. Reducing likelihood of instrumental delivery with epidural anaesthesia.
Lancet $2001 ; 358: 2$.

94 Fraser WD, Marcoux S, Krauss I, Douglas J, Goulet C, Boulvain M. Multicenter, randomized, controlled trial of delayed pushing for nulliparous women in the second stage of labor with continuous epidural analgesia. The PEOPLE (Pushing Early or Pushing Late with Epidural) Study Group. Am J Obstet Gynecol 2000; 182: 1165-72.

95 Viscomi CM, Manullang T. Maternal fever, neonatal sepsis evaluation, and epidural labor analgesia. Reg Anesth Pain Med 2000; 25: 549-53.

96 Kaul B, Vallejo M, Ramanathan S, Mandell G. Epidural labor analgesia and neonatal sepsis evaluation rate: a quality improvement study. Anesth Analg 2001; 93: 986-90.

97 Goetzl L, Cohen A, Frigoletto F Jr, Ringer SA, Lang $J M$, Lieberman E. Maternal epidural use and neonatal sepsis evaluation in afebrile mothers. Pediatrics 2001; 108: 1099-1101.

98 Camann W. Intrapartum epidural analgesia and neonatal sepsis evaluations. A casual or causal association? Anesthesiology 1999; 90: 1243-54.

99 Gaiser R. Neonatal effects of labor analgesia. Int Anesthesiol Clin 2002; 40: 49-65.

100 D'Alessio JG, Ramanathan J. Effects of maternal anesthesia in the neonate. Semin Perinatol 1998; 22: 350-62.

101 Ala-Kokko TI, Myllynen P, Vähäkangas K. Ex vivo perfusion of the human placental cotyledon: implications for anesthetic pharmacology. Int J Obstet Anesthesia 2000; 9: 26-38.

102 Celleno D, Capogna G, Emanuelli $M$, et al. Which induction drug for cesarean section? A comparison of thiopental sodium, propofol, and midazolam. J Clin Anesth 1993; 5: 284-8.

103 Sánchez-Alcaraz A, Quintana MB, Laguarda $M$. Placental transfer and neonatal effects of propofol in caesarean section. J Clin Pharm Ther 1998; 23: 19-23.

104 Herman NL, Li AT, Van Decar TK, et al. Transfer of methohexital across the perfused human placenta. J Clin Anesth 2000; 12: 25-30.

105 Gambling DR, Sharma SK, White PF, Van Beveren T, Bala AS, Gouldson R. Use of sevoflurane during elective cesarean birth: a comparison with isoflurane and spinal anesthesia. Anesth Analg 1995; 81: 90-5.

106 Abboud TK, Zhu J, Richardson M, Peres da Silva E, Donovan $M$. Desflurane: a new volatile anesthetic for cesarean section. Maternal and neonatal effects. Acta Anaesthesiol Scand 1995; 39: 723-6.

107 Kavak ZN, Basgül A, Ceyhan N. Short-term outcome of newborn infants: spinal versus general anesthesia for elective cesarean section. A prospective random- 
ized study. Eur J Obstet Gynecol Reprod Biol 2001; 100: 50-4.

108 Dick WF. Anaesthesia for caesarean section (epidural and general): effects on the neonate. Eur J Obstet Gynecol Reprod Biol 1995; 59(Suppl.): S61-7.

109 Kolatat T, Somboonnanonda A, Lertakyamanee J, Chinachot T, Tritrakarn T, Muangkasem J. Effects of general and regional anesthesia on the neonate (a prospective, randomized trial). J Med Assoc Thai 1999; 82: 40-5.

110 Ratcliffe FM, Evans JM. Neonatal wellbeing after elective caesarean delivery with general, spinal, and epidural anaesthesia. Eur J Anaesthesiol 1993; 10: 175-81.

111 Tsen LC, Pitner R, Camann WR. General anesthesia for cesarean section at a tertiary care hospital 19901995: indications and implications. Int J Obstet Anesthesia 1998; 7: 147-52.

112 Stuart KA, Krakauer H, Schone E, Lin M, Cheng E, Meyer GS. Labor epidurals improve outcomes for babies of mothers at high risk for unscheduled cesarean section. J Perinatol 2001; 21: 178-85.

113 Levy BT, Dawson JD, Toth PP, Bowdler N. Predictors of neonatal resuscitation, low Apgar scores, and umbilical artery $\mathrm{pH}$ among growth-restricted neonates. Obstet Gynecol 1998; 91: 909-16.

114 Reynolds F. Controversies: The drive for regional anaesthesia for elective caesarean section has gone too far - opposer position. Int J Obstet Anesthesia 2002; 11: 289-95.

115 Mueller MD, Brühwiler H, Schüpfer GK, Lüscher KP. Higher rate of fetal acidemia after regional anesthesia for elective cesarean delivery. Obstet Gynecol 1997; 90: 131-4.

116 Alabubta S, Jouppila P. How to maintain uteroplacental perfusion during obstetric anaesthesia. Acta Anaesthesiol Scand Suppl 1997: 106-8.

117 Emmett RS, Cyna AM, Andrew M, Simmons SW. Techniques for preventing hypotension during spinal anaesthesia for caesarean section (Cochrane Review). In: The Cochrane Library, Issue 1, 2003. Oxford: Update Software (CD-ROM).

118 Shearer VE, Ramin SM, Wallace DH, Dax JS, Gilstrap $L C 3 r d$. Fetal effects of prophylactic ephedrine and maternal hypotension during regional anesthesia for cesarean section. J Matern Fetal Med 1996; 5: 79-84.

119 Lee A, Ngan Kee WD, Gin T. A quantitative, systematic review of randomized controlled trials of ephedrine versus phenylephrine for the management of hypotension during spinal anesthesia for cesarean delivery. Anesth Analg 2002; 94: 920-6.

120 Ngan Kee WD. Obstetric neuraxial anaesthesia: which vasopressor should we be using? (Letter). Int J Obstet Anesthesia 2003; 12: 55-64.

121 Harrop-Griffiths W. Controversies: Ephedrine is the vasopressor of choice for obstetric regional anaesthesia - proposer position. Int J Obstet Anesthesia 2002; 11: 275-81.

122 Thomas DG. Controversies: Ephedrine is the vasopressor of choice for obstetric regional anaesthesia opposer position. Int J Obstet Anesthesia 2002; 11 : 275-81.

123 Cooper DW, Carpenter M, Mowbray P, Desira WR, Ryall DM, Kokri MS. Fetal and maternal effects of phenylephrine and ephedrine during spinal anesthesia for cesarean delivery. Anesthesiology 2002; 97: 1582-90.

124 Wright PM, Iftikhar M, Fitzpatrick KT, Moore J, Thompson $W$. Vasopressor therapy for hypotension during epidural anesthesia for cesarean section: effects on maternal and fetal flow velocity ratios. Anesth Analg 1992; 75: 56-63.

125 Jordan MJ. Controversies: Women undergoing caesarean section under regional anaesthesia should routinely receive supplementary oxygen - proposer position. Int J Obstet Anesthesia 2002; 11: 282-8.

126 Kelly MC, Fitzpatrick KT, Hill DA. Respiratory effects of spinal anaesthesia for caesarean section. Anaesthesia 1996; 51: 1120-2.

127 Cogliano MS, Graham AC, Clark VA. Supplementary oxygen administration for elective caesarean section under spinal anaesthesia. Anaesthesia 2002; 57: 66-9.

128 Saugstad OD, Rootwelt T, Aalen O. Resuscitation of asphyxiated newborn infants with room air or oxygen: an international controlled trial: The Resair 2 Study. Pediatrics 1998; 102: el. Available at: http://www.pediatrics.org/cgi/content/full/102/1 /el. (Accessed May 6, 2003).

129 Hill D. Controversies: Women undergoing caesarean section under regional anesthesia should routinely receive supplementary oxygen-opposer position. Int J Obstet Anesthesia 2002; 11: 282-8.

130 Saugstad OD. Update on oxygen radical disease in neonatology. Curr Opin Obstet Gynecol 2001; 13: 147-53.

131 Saugstad $O D$. Is oxygen more toxic than currently believed? Pediatrics 2001; 108: 1203-5.

132 Vento M, Asensi M, Sastre J, Garcia-Sala F, Pallardo $F V$, Vina J. Resuscitation with room air instead of $100 \%$ oxygen prevents oxidative stress in moderately asphyxiated term neonates. Pediatrics 2001; 107: 642-7.

133 Perlman JM. Resuscitation - air versus 100\% oxygen (Letter). Pediatrics 2002; 109: 347-9.

134 Halliwell $B$. Free radicals, antioxidants, and human 
disease: curiosity, cause, or consequence? Lancet 1994; 344: 721-4.

135 Vendemiale G, Grattagliano I, Altomare E. An update on the role of free radicals and antioxidant defense in human disease. Int J Clin Lab Res 1999; 29: 49-55.

136 Backe SK, Lyons $G$. Oxygen and elective caesarean section (Editorial). Br J Anaesth 2002; 88: 4-5.

137 Khaw KS, Wang CC, Ngan Kee WD, Pang CP, Rogers MS. Effects of high inspired oxygen fraction during elective caesarean section under spinal anaesthesia on maternal and fetal oxygenation and lipid peroxidation. Br J Anaesth 2002; 88: 18-23.

138 Hofmeyr GJ. Maternal oxygen administration for fetal distress (Cochrane Review). In: The Cochrane Library, Issue 1 2003. Oxford: Update Software (CD-ROM).

139 Halpern SH, Walsh VL. Multimodal therapy for postcesarean delivery pain (Editorial). Reg Anesth Pain Med 2001; 26: 298-300.

140 Rathmell JP, Viscomi CM, Ashburn MA. Management of nonobstetric pain during pregnancy and lactation. Anesth Analg 1997; 85: 1074-87.

141 Baka NF, Bayoumeu F, Boutroy MJ, Laxenaire MC. Colostrum morphine concentrations during postcesarean intravenous patient-controlled analgesia. Anesth Analg 2002; 94: 184-7.

142 Spigset $O$. Anaesthetic agents and excretion in breast milk. Acta Anaesthesiol Scand 1994; 38: 94-103.

143 American Academy of Pediatrics. Committee on Drugs. The transfer of drugs and other chemicals into human milk. Pediatrics 2001; 108: 776-89.

144 Goodman S. Anesthesia for nonobstetric surgery in the pregnant patient. Semin Perinatol 2002; 26 : 136-45.

145 Beilin $\Upsilon$. Anesthesia for nonobstetric surgery during pregnancy. Mt Sinai J Med 1998; 65: 265-70.

146 Yarnell $R W$. Emergency surgery during pregnancy. Winterlude 1995. Available at: http://www.anesthesia.org/winterlude/wl95/w195_6.html (Accessed May 5, 2003).

147 Goldenberg $R L$. The management of preterm labor. Obstet Gynecol 2002; 100(5Ptl): 1020-37.

148 Dufour P, Vinatier D, Puech F. The use of intravenous nitroglycerin for cervico-uterine relaxation: a review of the literature. Arch Gynecol Obstet 1997; 261: 1-7.

149 Cauldwell CB. Anesthesia for fetal surgery. Anesthesiol Clin North America 2002; 20: 211-26.

150 Smith RP, Gitau R, Glover V, Fisk NM. Pain and stress in the human fetus. Eur J Obstet Gynecol Reprod Biol 2000; 92: 161-5.

151 Rosen $M A$. Anesthesia for fetal procedures and surgery. Yonsei Med J 2001; 42: 669-80.
152 Report of the MRC group on fetal pain. 28 August 2001. Available at: http://www.mrc.ac.uk/pdffetal.pdf (Accessed May 5, 2003).

153 van Lingen RA, Simons SH, Anderson BJ, Tibboel D. The effects of analgesia in the vulnerable infant during the perinatal period. Clin Perinatol 2002; 29 : 511-34.

154 Thurlow JA, Kinsella SM. Intrauterine resuscitation: active management of fetal distress. Int J Obstet Anesthesia 2002; 11: 105-16.

155 Anonymous. Guidelines 2000 for Cardiopulmonary Resuscitation and Emergency Cardiovascular Care. Part 8: advanced challenges in resuscitation. Section 3: special challenges in ECC. The American Heart Association in collaboration with the International Liaison Committee on Resuscitation. Circulation 2000; 102(8 Suppl): I229-52.

156 Johnson MD, Luppi CJ, Over DC. Cardiopulmonary resuscitation. In: Gambling DR, Douglas MJ (Eds). Obstetric Anesthesia and Uncommon Disorders. Philadelphia: W.B. Saunders Company; 1998: 51-74.

157 Whitten M, Irvine LM. Postmortem and perimortem caesarean section: what are the indications? J R Soc Med 2000; 93: 6-9.

158 Katz VL, Dotters DJ, Droegemueller W. Perimortem cesarean delivery. Obstet Gynecol 1986; 68: 571-6. 